Occasional Hunts or Mass Kills? Investigating the Origins of Archaeological Pronghorn Bonebeds in Southwest Wyoming Author(s): Jack N. Fenner

Source: American Antiquity, Vol. 74, No. 2 (Apr., 2009), pp. 323-350

Published by: Society for American Archaeology

Stable URL: http://www.jstor.org/stable/20622429

Accessed: 10/02/2015 00:46

Your use of the JSTOR archive indicates your acceptance of the Terms \& Conditions of Use, available at http://www.jstor.org/page/info/about/policies/terms.jsp

JSTOR is a not-for-profit service that helps scholars, researchers, and students discover, use, and build upon a wide range of content in a trusted digital archive. We use information technology and tools to increase productivity and facilitate new forms of scholarship. For more information about JSTOR, please contact support@jstor.org. 


\title{
OCCASIONAL HUNTS OR MASS KILLS? INVESTIGATING THE ORIGINS OF ARCHAEOLOGICAL PRONGHORN BONEBEDS IN SOUTHWEST WYOMING
}

\author{
Jack N. Fenner
}

\begin{abstract}
It is often unclear whether an archaeological animal bonebed was formed by a mass kill of individuals from a single prey population or through the accumulation of a number of separate kills which occurred over a long time period or at multiple locations. The isotope ratio variation within animals from an archaeological bonebed can be used to investigate this question by comparing the isotope ratio variation within an archaeological assemblage to the variation within modern populations. If the archaeological variation exceeds that expected within a single population, then an accumulation is indicated. Otherwise, a single mass kill or a series of kills from a single population over a fairly short time period is more likely. This technique is demonstrated using carbon, oxygen, and strontium isotope ratios to characterize the amount of variation within pronghorn tooth enamel from six archaeological sites in southwestern Wyoming. The results indicate that the Austin Wash and Trappers Point sites are the result of an accumulation of pronghorn from multiple populations, while the Firehole Basin, Gailiun, and Boars Tusk sites do not show evidence of accumulation and therefore may be the result of mass kills. The Eden-Farson site formation characteristics are currently indeterminate.
\end{abstract}

\begin{abstract}
A menudo es difícil determinar si un depósito arqueológico de restos óseos de animal se formó a través de la muerte en masa de individuos de una única población de presas, o a través de la acumulación de un número de muertes por separado que tuvieron lugar durante un periodo de tiempo prolongado o en múltiples lugares. Es posible utilizar la variación de relaciones isotópicas en los animales de un depósito arqueológico de huesos para investigar dicha cuestión. La variación de relaciones isotópicas de un contexto arqueológico es comparada con la variación en de población moderna y, si la variación arqueológica supera aquella que se espera dentro de una única población, se indica una acumulación. De otra manera, es más probable una única muerte en masa o una serie de muertes de una única población a lo largo de un periodo de tiempo relativamente corto. Dicha técnica queda demostrada mediante el uso de relaciones isotópicas de carbono, oxígeno y estroncio para caracterizar la magnitud de la variación en el esmalte de dientes de antílopes americanos proveniente de seis yacimientos arqueológicos del sudoeste de Wyoming. Los resultados indican que los yacimientos de Austin Wash y Trappers Point son el resultado de una acumulación de antilocapras americanas de diversas poblaciones, mientras que los yacimientos de Firehole Basin, Gailiun y Boars Tusk no presentan evidencia de acumulación y por lo tanto pueden ser el resultado de muertes en masa únicas. Las características de la formación del yacimiento de Eden-Farson aún no han sido determinadas.
\end{abstract}

$\mathrm{P}$ ronghorn (Antilocapra americana) roam wild on Wyoming rangelands today as they have for many millennia. Archaeological evidence indicates that people have successfully hunted these fairly large and very fleet animals for at least 13,000 calendar years (Frison 1991; Hill 2001; Lubinski 2000a), which in some instances has led to substantial archaeological pronghorn bonebeds. As is often the case for archaeological bonebeds, it is difficult to determine whether a particular pronghorn bonebed resulted from a single mass kill or from an accumulation of multiple kills over time. This is an important question because it has implications for a variety of human behaviors of archaeological interest. An improved understanding of prehistoric mass kill strategies in general, and pronghorn procurement in particular, would affect not only the interpretation of site occupation histories, but also larger issues such as the prevalence of communal hunting and population aggregation (Arkush 1986; Davis et al. 2000; Fawcett 1987; Lubinski 1999), resource intensification (Lubinski 1997), population size and mobility (Todd 1987; Widga 2004), gender roles and meat

Jack N. Fenner $\square$ Department of Archaeology and Natural History, The Australian National University, Canberra ACT 2600, Australia (jack.fenner@anu.edu.au) 
sharing (Dewar et al. 2006), and cultural or technological change (Lubinski 1997, 2000a; Ugan et al. 2003).

Much of our understanding of mass procurement events derives from ethnographic and historical sources. Within western North America, traditional peoples communally mass-hunted bison (De Smet 1859), rabbits (Chamberlin 1911:336; Steward 1933:253-254), deer (Steward 1933:252, 1938:82-83), and even insects such as crickets (Egan 1917:230-233). Of particular interest to this study are numerous reports of historic communal pronghorn hunts (Arkush 1986; Egan 1917: 238-241; Grinnell 1923:277-290; Hyde 1968:18-20; Irving 1986:225-226, 353-354; Kelly 1932:82-86; Kindig 1987; Lowie 1909:185, 1924:197; Lubinski 1999; Steward 1938:34-36, 105, 115, 120, 128, 175, 233; Sundstrom 2000). Pronghorn herds were driven or led into brush or timber corrals, driven into pits, or surrounded by people either on foot or horseback. The pronghorn were often then run to exhaustion, at which point they could be easily killed. There are also numerous accounts of individual pronghorn hunting, using disguises to stalk pronghorn (e.g., Lowie $1909,1924)$ or colored flags that flap in the wind and attract curious pronghorn (e.g., Chittenden 1905; Schoolcraft 1860). While valuable, these accounts lack time depth and may reflect responses to Euroamerican contact rather than traditional prehistoric behavior. For a long-term perspective, we must turn to archaeology.

Unfortunately, the use of archaeology to understand communal mass-kill behavior is often hampered by an inability to reliably distinguish between sites that contain the remains of large kills from a single population and those containing an accumulation of small, presumably noncommunal kills obtained from multiple prey populations. Hoppe (2004) and Widga (2004) recently and independently introduced a technique that uses isotope ratio analysis to investigate this issue. Simply put, a site whose prey remains contain more isotopic variation than is found in a single modern prey population is likely to be the result of an accumulation from multiple populations and therefore probably is not the result of a single mass kill. Conversely, if the isotopic variation within a site is less than or equal to that found in modern populations, then there is no evidence of accumulation from multi- ple populations and a single mass kill (or a series of fairly closely related kills from a single population) is more likely.

Hoppe (2004) assessed the carbon, oxygen, and strontium isotope ratio variation of two paleontological mammoth bonebeds thought to represent catastrophic herd mortality, and decided that only carbon isotopes showed sufficient inter-herd variation to confidently distinguish between herds. She then compared the carbon isotope variation in the paleontological mass mortality bonebeds to the variation within the Blackwater Draw, Miami and Dent mammoth archaeological assemblages. Her analysis suggests that all three assemblages are composed of mixtures of individuals from multiple herds (Hoppe 2004:139) and therefore likely represent multiple kill events within each site.

Widga (2004:38-41), as part of a larger analysis of Early Archaic bison procurement, compared the carbon isotope variation within bison remains recovered from several components of the Spring Creek and Logan Creek sites in Nebraska to that of bison remains from Paleoindian mass kill components at the Agate Basin site and the multiplekill Plains Village sites of Helb and Talking Crow. He found that Spring Creek and at least one Logan Creek component appear to represent singleepisode procurement events. Widga $(2004: 39,41)$ acknowledges that the comparative samples from differing time periods are of uncertain comparative value, and that a number of untested assumptions are included in his isotopic analysis. Nevertheless, a qualitative assessment of the range of variation suggests that bison mass kill sites may have substantially less carbon isotope variation than do multiple kill sites (Widga 2004:41).

These interesting studies introduce a technique that promises to improve our understanding of prehistoric hunting practices. The study reported here further analyzes and develops isotopic characterization of bonebeds along several lines. Both Hoppe and Widga used ancient animal remains thought to result from known mortality events as comparative samples to characterize unknown mortality events. This was necessary because the animals used in those studies (mammoth and bison) no longer roam wild, so no modern sample set was available. Although partially circumscribed by fences and other artificial structures, pronghorn remain wild within Wyoming and therefore provide a good com- 


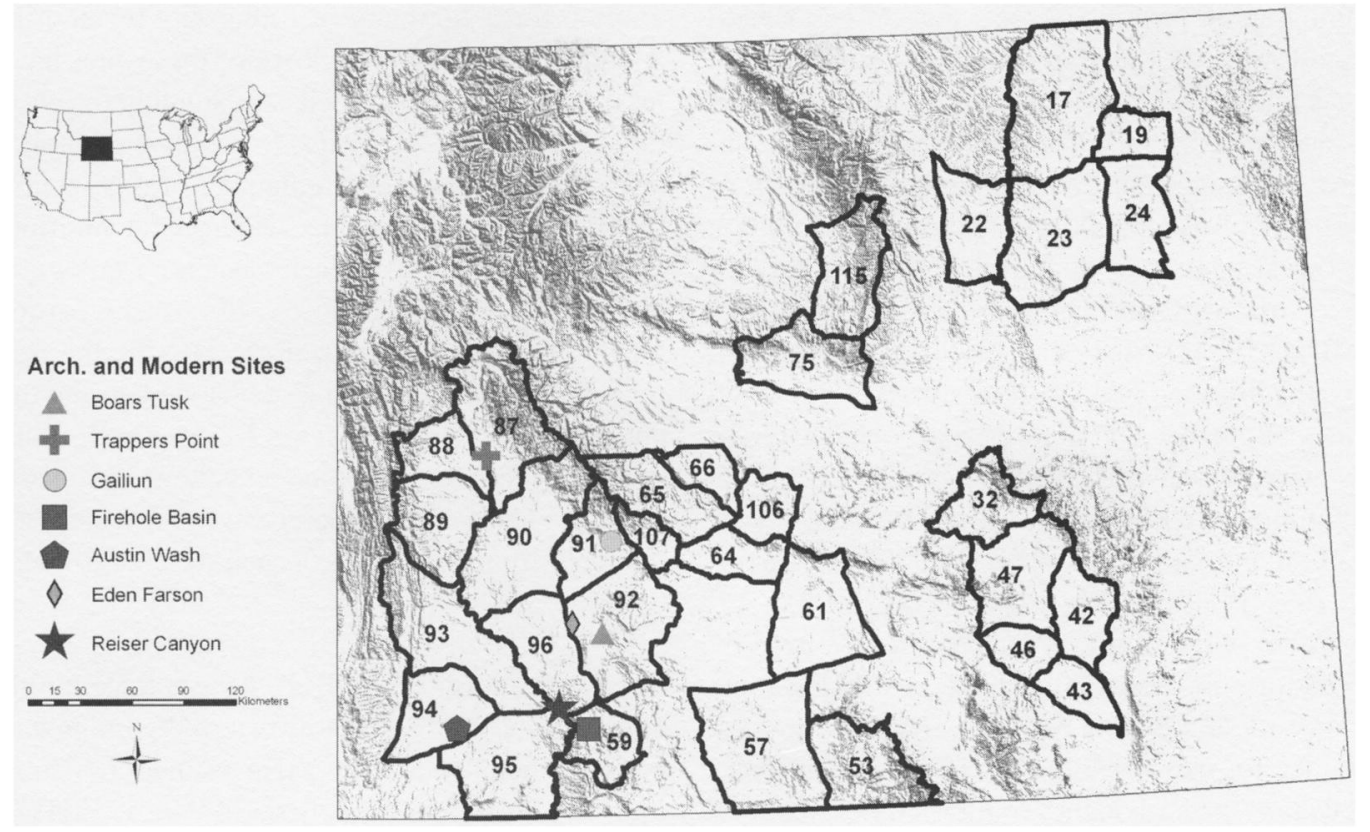

Figure 1. Wyoming pronghorn bonebeds and hunt areas.

parative sample for assessing archaeological isotope ratio variation. My study also expands upon the Hoppe-Widga work by using a scaling and distance approach that simultaneously incorporates isotopic information from multiple elements, and a bootstrap technique that provides quantitative comparisons of isotopic variability between locations.

The isotope ratio analysis technique is used to investigate the formation processes of bonebeds from six archaeological sites in southwestern Wyoming: Austin Wash (48UT390), Boars Tusk (48SW1373), Eden-Farson (48SW304), Firehole Basin (48SW1217), Gailiun (48SW1156), and Trappers Point (48SU1006) (Figure 1). The carbon, oxygen, and strontium isotope ratios are measured in enamel collected from pronghorn teeth found within bonebeds at each of these sites. The amount of isotopic variation within each site is computed and compared with modern pronghorn populations to assess whether the pronghorn remains at the site were obtained from multiple pronghorn populations (and therefore likely represent multiple mortality events). The number of mortality events at each of these sites has previously been analyzed using traditional methods. Before presenting details of the current project and its results, a brief review of these traditional methods and their results is in order.

\section{Previous Work}

Archaeologists confronted with substantial prehistoric bonebeds currently use a number of criteria for assessing whether a particular archaeological faunal assemblage is the result of a single mass kill or the accumulation of multiple kill events (e.g., Davis et al. 2000; Frison 2000; Hill 2002; Lubinski 1997, 2000a; Todd et al. 1992, 2001; Widga 2004). Lubinski (1997:124-206, 2000a) provides a detailed discussion of many of these criteria as they relate to identification of a pronghorn mass kill. $\mathrm{He}$ separates the criteria into three categories: evidence for human-caused mortality (e.g., association with projectile points or presence of cut marks), evidence for a single depositional episode (e.g., stratigraphic association), and evidence for a single mortality event. The work discussed in this paper is particularly concerned with the last category, which Lubinski evaluates using two types of evidence: uniform season of death and presence of a catastrophic demographic profile. A uniform season of death is evidence that the animals died within a fairly narrow window of time, while a catastrophic 
demographic profile suggests that an entire herd may have been killed at once. However, each of these lines of evidence has difficulties. The season of death may be uncertain. This is a particular concern for pronghorn bonebeds because season of death analyses typically depend on tooth eruption and wear techniques that in pronghorn often produce very wide seasonality ranges (Lubinski and O'Brien 2001; Miller et al. 1999b:483). Additionally, the bonebed may be the result of multiple kill episodes during the same season over differing years without discernable stratigraphic separation (as might be expected if the kill episodes are dependent on animal migration [Hill 2002:331; Lubinski 1997:198; Lubinski and O'Brien 2001]).

Tooth eruption and wear patterns are used by prehistorians-especially those evaluating large prehistoric bison bonebeds--to develop prey age profiles for use in estimating herd demographics as well as the seasonality of mortality events (Frison 1978, 1991; Frison and Reher 1970; Todd et al. 1992; but see Whittaker and Enloe 2000). More generally, catastrophic (or "non-selective") prey age demographic profiling is used to distinguish between bonebeds created by animal predation, human hunting, and human scavenging (e.g., Klein 1982; Stiner 1990, 1991a, 1991b). Catastrophic age profiles are those that reflect a "normal" age profile for the species in question and are thought to indicate that an entire herd or population died all at once in a mass mortality event. The use of catastrophic age profiles to identify mass kills is controversial (Caughley 1974; Lubinski 2000b; Lyman 1987; Steele 2003; Whittaker and Enloe 2000). For age profiles to be acceptable mortality indicators, the animal population in question must have a stable population level, a consistent normal living age structure, and a clear age indicator. Wildlife biologists have rejected the use of age profiles in wildlife management and moved to more complex population models that incorporate many variables that cannot be determined in archaeological situations (e.g., animal densities on different range types; see Kohlmann [2004] for modern pronghorn population modeling discussion).

Despite these concerns, Lubinski (1997, 2000a, $2000 \mathrm{~b}$ ) has used uniform season of death and presence of a catastrophic demographic profile as criteria to assess formation history at five of the six archaeological sites discussed in this report (see
Table 6 for a summary of Lubinski's results). In addition, investigators at some of these sites have used other techniques, such as evaluating the clustering of radiocarbon dates, to assess the number of mortality events. The remainder of this section describes the non-isotopic evidence for multiple prey populations within each of six archaeological pronghorn bonebed sites in southwestern Wyoming. Subsequent sections describe the isotope ratio variation evidence developed during the current project. Finally, in the Discussion section, the combined non-isotopic and isotope ratio variation evidence is considered and the pronghorn population characteristics of each site are assessed.

\section{Austin Wash}

The Austin Wash site (48UT390) is a large multicomponent locality in southwestern Wyoming that has been the subject of several investigations (Reiss and Walker 1982; Schroedl 1985; SHPO 1981-1999). It is "situated on the upper of two terraces above and just west of the confluence of Austin Wash and an unnamed, ephemeral drainage that flows from the northwest" (Schroedl 1985:35). Two early components of the site have been radiocarbon dated to $3030 \pm 70$ B.P. and $1740 \pm 60$ B.P. The component of interest for the present analysis is a large pronghorn bonebed in the northern portion of the site that has been radiocarbon dated to $1197 \pm 26$ B.P. Except where specifically noted, references to Austin Wash in this report refer to this component. No cultural or geological stratification is visible within the component, and all materials were recovered within $40 \mathrm{~cm}$ of the present ground surface. In addition to pronghorn, the remains of at least two bison, one canid, and a handful of small, possibly intrusive, rodents and rabbits were recovered. The pronghorn, bison, and canid bones exhibit cut marks.

In the most detailed report available on the Austin Wash site, Schroedl (1985:91) indicates that "analysis of the radiocarbon dates..., the distribution of the artifacts and the faunal remains, and the cohesiveness of the artifact assemblage all indicate that the main excavation area [the pronghorn bonebed] represents a single, short-term antelope processing locale." His ANOVA analysis of six radiocarbon dates from the component indicated that they are not significantly different. This is supported by the radiocarbon clustering method of 


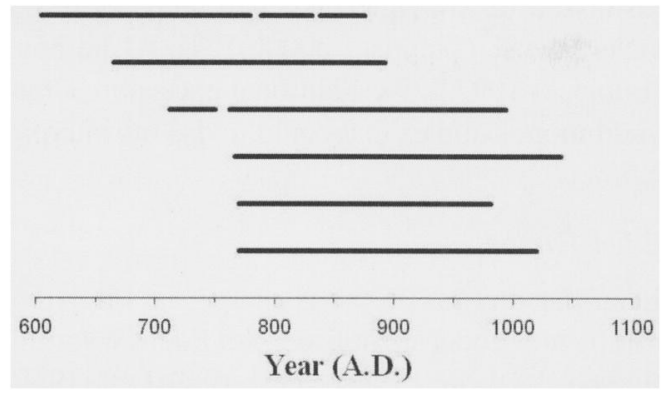

Figure 2. Austin Wash pronghorn bonebed radiocarbon dates. The 95 percent confidence intervals are shown for the six radiocarbon dates from the bonebed component (Beta 2444, 3325, 7271 - 7274). Weighted average: $1197 \pm$ 26 B.P.; Cal. A.D. 724 to 739 and 771 to 893.

Wilson and Ward (1981), which does not find significant structure within the dates $\left(\mathrm{T}^{\prime}=9.07 ; p>\right.$ .05). Likewise, using a current radiocarbon calibration curve (BCal 2006), the 95 percent confidence intervals for the six dates overlap for most of the period between A.D. 770 and 876 (Figure 2). Note, however, that they also present a spread of 435 years. The radiocarbon date overlap therefore supports a single contribution to the bonebed, but the dates also include sufficient uncertainty to also be consistent with multiple contributions that accumulated over a time period of up to several hundred years.

Schroedl's reference to the distribution of the artifacts apparently relates to the fact that the stone and bone artifacts are concentrated in the same area. It is not clear what is meant by the "cohesiveness" of the artifact assemblage, unless it refers to consistency in the temporally diagnostic stone tool collection. Schroedl (1985:50-56) identified 16 of 18 temporally diagnostic projectile points found within the pronghorn bonebed as "Rose Spring" type. The other two points were identified as Avonlea (thought to be diagnostic of the Late Prehistoric period) and Lovell Constricted. The Lovell Constricted point is interesting as it is a late Paleoindian point type (Frison 1991). Schroedl (1985:55) states without further discussion that "although recovered from within the bone midden, it does not represent an earlier occupation in the midden area." Such an early point does seem out of place and probably can be dismissed as intrusive to the bonebed, but perhaps it hints at a weakness in the cohesiveness of the collection.
Lubinski (1997:226-242, 2000a, 2000b) analyzed the pronghorn mortality pattern at Austin Wash and concluded that the evidence is "inconsistent with a single mass kill event" (Lubinski 1997:242). His seasonality assessment was inconclusive because it was based on three samples that produced mortality periods that overlap from October to January but range from July to April. As previously noted, this broad range is common in pronghorn tooth-based seasonality assessment (Lubinski 2001; Lubinski and O'Brien 2001) and provides little insight into the number of mortality events. His assessment of age demographic structure indicates that Austin Wash "appears to have too many mature animals for a living structure" (Lubinski 2000b:124), which leads him to conclude that Austin Wash was not a mass kill or mortality site.

\section{Firehole Basin \#11}

The Firehole Basin \#11 site (48SW1217; generally referred to herein as simply Firehole Basin) lies on a hill between the Green River and Little Bitter Creek. It was excavated during 1976 and 1977, but has been only partially reported (Lubinski 1997, 2000a; Middleton et al. 2007). Thirty-four test units were excavated, although many of the units were dug only five centimeters below the surface. Nevertheless, a substantial bone, lithic, and ceramic assemblage was recovered. Lubinski (1997:243245 ) indicates that hafted "Shoshonean" knives, ceramics, tri-notched projectile points, and two radiocarbon dates of $645 \pm 135$ B.P. (cal A.D. 1159 to 1469 ) and $625 \pm 50$ B.P. (cal A.D. 1283 to 1406 ) all support Late Prehistoric to Protohistoric affiliation. The bonebed includes at least 26 pronghorn individuals, plus five rabbit bones, three pocket gopher mandibles, and one sage grouse bone (Middleton et al. 2007). Lubinski (1997:245) reports that two bison bones from Firehole Basin were examined in 1986, though they were subsequently lost. In any case, the faunal assemblage was clearly dominated by pronghorn.

Lubinski's (1997:249) eruption and wear analysis of seven Firehole Basin mandibles produced seasonality estimates that ranged from August to April and overlapped during December and January. Seasonality analysis therefore is not helpful in assessing the number of mortality events. Lubinski also assessed age demographics using Juvenile/ 
Prime/Old (JPO) partitions and Fawn/Youth/ Mature (FYM) partitions, as well as a histogram of annual age categories (Lubinski 1997:249-253, $2000 \mathrm{~b}$ ), all of which were derived from pronghorn mandibles. When compared to his model distributions, two of these measures (FYM and histogram) most closely resemble an entire living population and therefore suggest a mass kill, while the third (JPO) is more compatible with an attritional mortality pattern. His assessment is that, on balance, "the mass kill hypothesis is most parsimonious and Firehole Basin is evaluated as a single mass kill" (Lubinski 1997:253-254).

\section{Gailiun}

The Gailiun site (48SU1156) was partially excavated during 1978 and 1990 but has not been formally reported. Thus we must rely on Lubinski's $(1997,2000$ a) pronghorn bonebed analysis publications for site information. The site is located on an alluvial silt terrace along Dry Sandy Creek. It includes five shallow depressions with artifact clusters that Bill Current, who excavated the site in 1990 , identified as the remains of five structures (Current 1993, cited in Lubinski 1997:271). Four $2 \times 2 \mathrm{~m}$ units and one $1 \times 1 \mathrm{~m}$ unit were excavated; the depth of excavation is not known but was apparently very shallow. Artifacts recovered include ceramics, lithics, and bone. Despite a radiocarbon date of $150 \pm 60$ B.P. (cal A.D. 1646 to 1892) on charcoal recovered from the 1978 excavation, no Euroamerican trade goods were recovered. Though some 5,500 bone fragments were collected during the 1978 and 1990 excavations, it is likely that these represent only a small proportion of the bone present at the site (Lubinski 1997:273).

Lubinski's (1997:276-277) seasonality analysis of pronghorn mandibles from Gailiun did not yield useful information. Most specimens produced age estimates exceeding six months in duration. Only one specimen produced a reasonable range, from August to January. Mandible-based seasonality therefore cannot inform us regarding the number of mortality events. No old adults were present in the Gailiun sample so the JPO age analysis is not applicable, and no fawns were present so the FYM age analysis also cannot be applied. Likewise, there are insufficient samples to produce a meaningful histogram of age categories. Lubinski nevertheless states that "Gailiun clearly should be dismissed [as a single mass kill site] because it lacks fawns" (Lubinski 2000b:124). As he notes (Lubinski 1997:279), additional excavations may yield more samples that could revise his interpretation.

\section{Eden-Farson}

Eden-Farson (48SW304) is a large site located on rolling hills about six miles east of Eden, Wyoming (Frison 1971, 2000; Larson et al. 1969; Lytle 1969). The Wyoming Archaeological Society excavated a substantial portion of the site during 1969 and 1970. Additional material was collected from exposed areas during subsequent visits, but it appears that substantial additional material was lost due to looting. Eden-Farson has been interpreted as a protohistoric Shoshonean occupation. It includes a number of post holes, depressions, hearths, and bone debris piles that are interpreted as evidence of ten habitations or lodges. The remains of at least 226 pronghorn were recovered. Though the EdenFarson faunal collection is dominated by pronghorn remains, relatively small amounts of bison, canid, rabbit, sage grouse, and rodent remains were also recovered. The vertebrae of large trout were present and may have been used as beads, but no other fish remains were recovered (Frison 1971:266).

Nimmo (1971) estimated the age at death of 79 Eden-Farson pronghorn and created a histogram of the population age structure. He then visually compared this histogram to age distributions of a Dall Sheep attritional death collection and a catastrophic death assemblage of Merycodus furcatus (an extinct Antilocapridine). The Eden-Farson histogram clearly resembles the catastrophic death assemblage profile, which Nimmo (1971) and Frison (2000) accept as strong evidence that Eden-Farson was the result of a very large population kill rather than a series of attritional kills.

Lyman (1987) critiques Nimmo's (1971) analysis on the grounds that old pronghorn individuals are absent from the Eden-Farson assemblage. Lyman raises the possibility that the pronghorn had "steepened their survivorship curve" (1987:140); that is, that older individuals were absent from the parent population due to hunting pressure. This might cause the population age structure histogram to not conform to expected catastrophic or attritional age profiles. So, while Lyman does not claim that Eden-Farson's pronghorn remains are neces- 
sarily the product of an attritional mortality sequence, his analysis questions the large population kill scenario.

Lubinski (1997:254-269), as usual, begins his investigation of Eden-Farson pronghorn mortality with a seasonality analysis. With such a large sample, he is able to disregard pronghorn mandibles whose seasonality estimate ranges exceed six months. This leaves 90 mandibles with individual seasonality estimates of six months or less, which when combined produce an assemblage seasonality estimate that spans the entire year. However, 93 percent of the season estimates include the October to January period. Lubinski therefore indicates that "most of the kills at Eden-Farson occurred from fall to mid-winter" (1997:263). His age structure analyses produced conflicting results, with the JPO partition conforming to an accumulation of multiple events but the FYM partition and age histogram more closely resembling a single population. Because two of the analyses favored a single population, Lubinski considers Eden-Farson to be "more consistent with a single mortality event than multiple events" (1997:267).

\section{Boars Tusk}

The Boars Tusk site (48SW1373) is in the Green River Basin, about $2.4 \mathrm{~km}$ southeast of the prominent volcanic formation of the same name (SHPO 1979). It was partially excavated in 1981 , and summary results were reported by Fisher and Frison (2000; see also Lubinski 1997:279-287). Boars Tusk contains at least 11 concentrations of heataltered rock, artifacts, bone, and charcoal laid out in a roughly linear, or perhaps oval, configuration. Five of these concentrations have been excavated. Boars Tusk is considered a Late Prehistoric or Protohistoric site based on diagnostic projectile points and a single radiocarbon date of $100 \pm 80$ B.P. (cal A.D. 1653 to 1919). Not all of the artifacts from Boars Tusk were included in the summary publication, but in addition to projectile points they include at least six bifaces, four unifaces, a scraper, a core, a mano, and four bone beads. No Euroamerican trade goods are reported. Pronghorn remains dominate the faunal collection, with at least nine pronghorn individuals present (Lubinski 1997:282). The only other identified animals are one rabbit and one or two rodents, though three bison-sized but unidentifiable bones were also recovered.
Fisher and Frison assessed the season of death using six mandibles and two maxillae whose teeth had not fully erupted. They estimate a season of death between October and January, with "the preponderance of evidence pointing to somewhere during November-December" (Fisher and Frison 2000:91). Because of the wide range of variation in a fairly small sample, they were unable to resolve whether Boars Tusk was the result of a mass kill or an accumulation from multiple kills.

Lubinski (1997:284) was only able to assess the season of death for one pronghorn mandible, which produced an estimate ranging from August to January. This is obviously of little use in assessing the site formation process. His age-based analyses were also hindered by small sample sizes, which prevented him from performing the JPO or age histogram analyses. His FYM analysis was "largely consistent" (Lubinski 1997:285) with a mass kill mortality event, but overall Lubinski (1997:287, 2000:124) considers the Boars Tusk mortality event analysis to be inconclusive.

\section{Trappers Point}

Trappers Point (48SU1006) is a large, multicomponent pronghorn bonebed site just west of Pinedale, Wyoming, that was partially excavated between 1990 and 1992. Excavation results have been reported (Miller et al. 1999a; Miller and Sanders 2000; Sanders and Miller 2004) and analysis continues (Clayton and Kunselman 2002; Fenner and Walker 2008; Leopold and Vita-Finzi 2005). Pronghorn remains were recovered from several components, but the current analysis only concerns bones from Stratum V, an Early Archaic component that contains the most extensive bonebed at the site. The Stratum V excavation produced many stone tools, several features, and abundant animal bone. About 85 percent of the identified bone is from pronghorn; the remainder is distributed in low percentages among bison, elk, deer, grouse, and small mammals such as voles and rabbits. One goose bone and one fish bone were also recovered. Except as specifically noted, all references to Trappers Point in this article refer specifically to Trappers Point Stratum V.

Miller et al. (1999a) used several avenues of evidence to assess the number of Trappers Point mortality events. Their general conclusion was that the bonebed likely represents a single mortality 


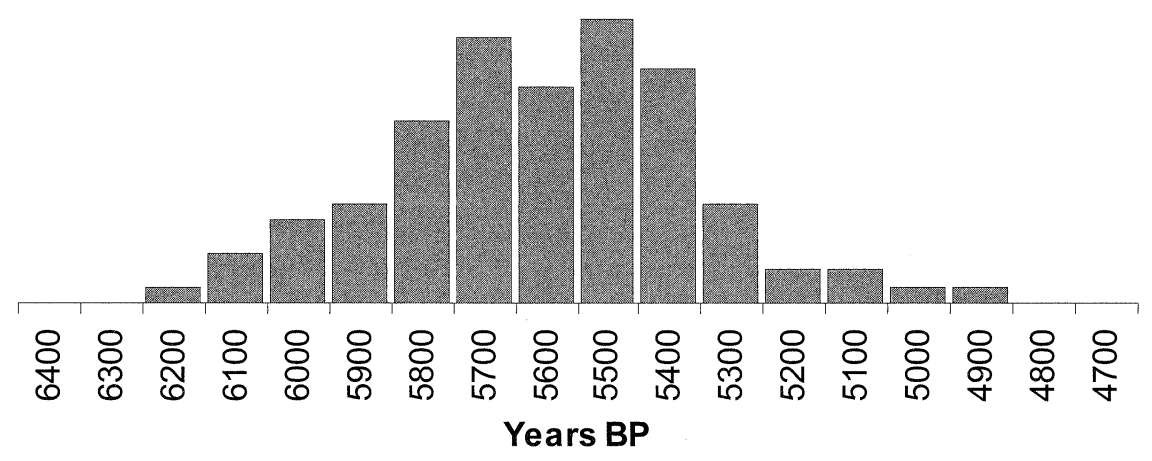

Figure 3. Histogram of combined Trappers Point Stratum V radiocarbon date probability distributions using 18 bins. Redrawn from Francis and Sanders 1999:Table 5.2, which is based on a 1993 version of Kintigh's C14 program.

event, or possibly a series of events within a single season of one year. The evidence did not, however, permit firm conclusions: "Unfortunately, investigators cannot demonstrate unequivocally whether or not the bonebed represents a single cohort kill or separate closely spaced spring events in a single year" (Miller et al. 1999b:283).

Eleven radiocarbon dates from Trappers Point range from $5160 \pm 210$ to $6010 \pm 130$ B.P. The probabilities associated with the normal distributions for these dates were summed and graphed, resulting in a "fairly steep unimodal curve" (Francis and Sanders 1999:49) (Figure 3). This is interpreted as supporting a single occupational event, because a continuous occupation over the entire time span would likely produce a flatter distribution. However, one could also make a case that the distribution in Figure 3 is, in fact, fairly flat and bimodal with modes at 5700 and 5500 B.P. As the apparent bimodality could be an artifact of the large bin size used in Figure 3, the 11 Trappers Point radiocarbon date probability distributions have been combined and graphed using a much finer-grained histogram binning size (not shown; see Fenner 2007:95). It is clear from the fine-grained histogram that there are at least two true modes, with a possible third mode around 6000 B.P. There are, of course, any number of intermittent occupation patterns that could produce such a distribution. Furthermore, Bartlein et al. (1995) has shown that, in some circumstances, modality in uncalibrated radiocarbon date histograms can be the result of fluctuations in atmospheric radiocarbon production as reflected in non-linearity in calibration curves, and therefore modality is not necessarily related to the number of occupations.
This issue can more profitably be addressed using a statistical approach. Using Wilson and Ward's (1981) radiocarbon date clustering analysis method, the 11 Stratum $V$ radiocarbon dates are not a single cluster $\left(T^{\prime}=21.97 ; p<.02\right.$; test includes sunspot effect uncertainty for all samples).

The radiocarbon data may also be examined using calibrated dates (Figure 4). The 95 percent confidence intervals of some dates do not overlap. In particular, sample 79197's interval does not overlap with the intervals for 79195 or 79191 . The interval for 79191 also does not overlap with that of 79194 or 53885. Assuming the dated material was deposited simultaneously with the bonebed it was found within, the lack of overlap indicates that the bonebed resulted from at least two depositional episodes.

Miller interprets an age distribution histogram based on fetal bone and tooth eruption/wear analyses (Figure 5) as indicating "catastrophic [i.e., nonnatural] mortality of pronghorn dominated by mature, breeding age individuals" (Miller 1999:240). An age structure dominated by mature, breeding individuals suggests hunter selection for prime animals (and therefore an accumulation from multiple kills) rather than a mass kill of all individuals in a population. However, the near absence of pronghorn over three years of age raises concern. As Lyman (1987:140) pointed out for the Eden-Farson sample, pronghorn may have had a steep survivorship curve, perhaps due to predation by humans. This concern, in combination with the known imprecision involved in aging pronghorn based on tooth wear (Lubinski 2001; Miller et al. 1999b:483) and likely variability in age profiles due to natural events such as severe winters, prevents 


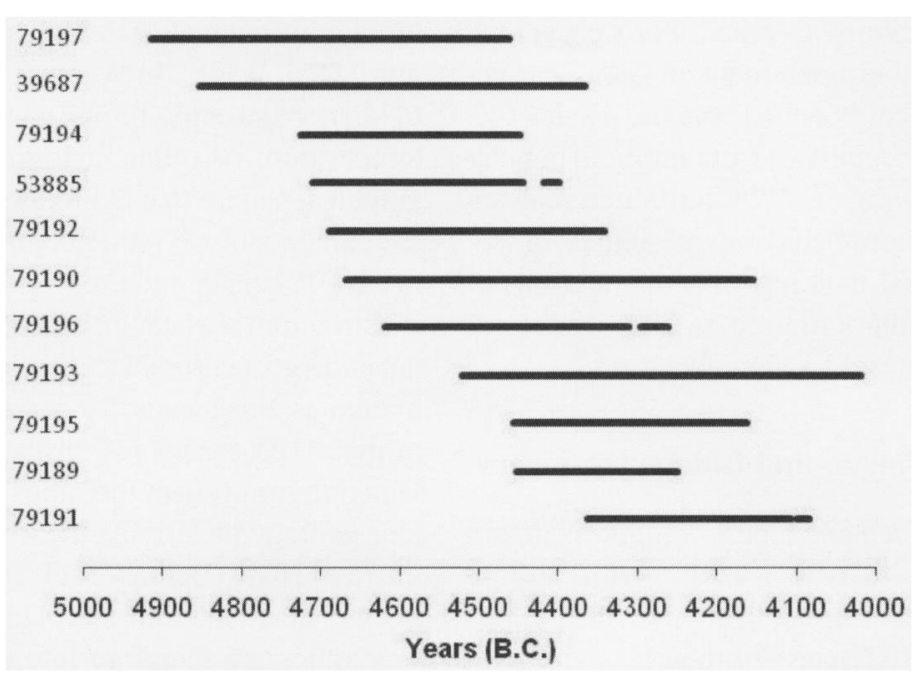

Figure 4. Calibrated Trappers Point Stratum V radiocarbon dates. The 95\% confidence intervals are shown. The only AMS-measured date is the second from the bottom. Data from Francis and Sanders 1999:42. Beta samples 39687, 53885, 79189-79197. Calibration from BCAL 2006.

age profiles from being used to assess a hypothesis of multiple pronghorn accumulations at Trappers Point.

Miller et al. (1999a) also examined maps of the vertical distributions of pronghorn bones. These maps show a "single, relatively compact, 10 to 20 $\mathrm{cm}$ thick bone layer. There is no evidence for vertically separate bone layers, which agrees with the field observations" (Sanders 1999:389). This is strong evidence for either a single kill or accumulations that were very closely spaced in time. The maps in question, however, are drawn east-to-west and therefore do not address potential vertical separation along other axes. Sediment deposition rates are unknown in the Trappers Point area and the bones may have been on or near the surface for a

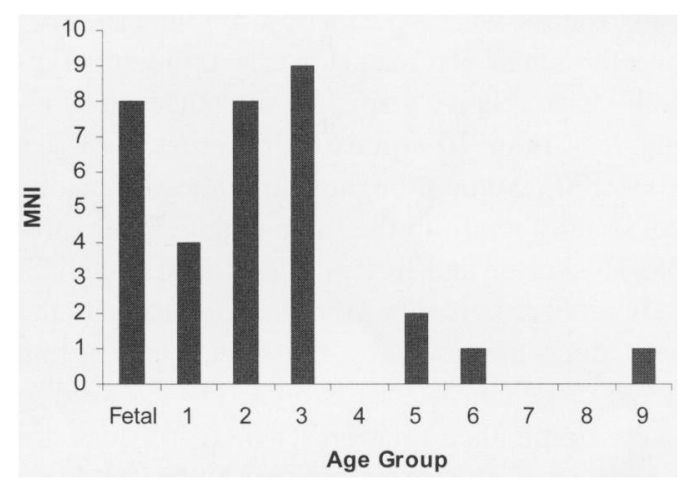

Figure 5. Trappers Point pronghorn age profile. Redrawn from Miller 1999:Figure 11.14. considerable number of years.

Trappers Point fetal pronghorn mortality seasonality estimates are compatible with a single kill event, though there are hints of structure within the date estimate distribution that suggest two or three kill events may have occurred (Fenner 2007; Fenner and Walker 2008). Of course, the fetal pronghorn data only addresses kills of mature pregnant females in late winter and spring. Other kill events involving males or occurring during other seasons would not be detected through analysis of fetal remains.

To summarize the results for Trappers Point so far, radiocarbon dates indicate that there were multiple occupations separated by substantial time periods, pronghorn age distribution data is not informative, vertical distribution maps support but do not demonstrate a single kill or multiple kills fairly closely spaced in time, and fetal seasonality data are compatible with a single kill event but do not rule out additional events.

This review demonstrates that the pronghorn population formation processes at these six sites is difficult to interpret using current techniques. Seasonality and age distribution patterns are often inconclusive or conflicting, and radiocarbon date cluster analysis may not be precise enough (or may lack sufficient samples) to resolve the issue. Isotope ratio variation analysis offers an independent means of assessing prey population characteristics 
that, in combination with other approaches, may permit more reliable assessment of whether a specific archaeological bonebed was the result of an accumulation of pronghorn from multiple populations. The following sections introduce relevant aspects of pronghorn behavior and sources of isotope variation, and then report on the analysis of pronghorn isotopic variation at each of the six archaeological sites discussed above.

\section{Pronghorn Behavior and Isotope Chemistry}

Though often called antelopes, pronghorn are not closely related to true Eastern Hemisphere antelopes but instead are indigenous to the prairies of North America. Aspects of their behavior relevant to isotope analysis have been presented elsewhere (Fenner 2007, 2008) and will only be briefly summarized here. More detailed discussions of pronghorn biology and behavior are also available (McCabe et al. 2004; O'Gara and Yoakum 2004). Pronghorn are ruminants that forage primarily on shrubs (most of which are sagebrush species in Wyoming) with forbs and occasionally grasses providing smaller contributions to the diet (Yoakum 2004a:465-466). Most such plants utilize the C3 photosynthetic pathway, resulting in carbon isotope ratios that range from about -20 to -35 per mil (\%o) (Ehleringer and Rundel 1989). Pronghorn enamel therefore shows a strong C 3 signal (after adjustment for dietary fractionation). Within the $\mathrm{C} 3$ range, pronghorn carbon isotope ratios have been shown to have significant geographic variation both across Wyoming in general and within southwestern Wyoming in particular, probably as a result of consuming plants that grew in differing humidity regimes (Fenner 2007; Fenner and Frost 2009).

Oxygen isotope ratios in mammal tissues are derived from body water, which includes drinking water, water obtained directly from food, and metabolic water produced by oxidation of food (Koch 1998). The oxygen isotope ratios in rain and snow are determined by temperature and the number of previous rainouts, and may also be affected by aridity (Clark and Fritz 1997; Higgins and MacFadden 2004; Levin et al. 2006). Prior to consumption by pronghorn, oxygen isotope ratios in local water may be further affected by other factors, such as evaporation enrichment within plant leaves or transport via river channels. Oxygen isotope ratios in pronghorn enamel therefore are controlled by a number of factors. In Wyoming, the ratios appear to be more strongly influenced by aridity than by temperature or other factors, and show a geographical pattern that is similar but not identical to the carbon isotope ratio geographic pattern (Fenner 2007; Fenner and Frost 2009).

Strontium is a heavy element whose isotopes do not undergo measurable biological fractionation. In mammals, this means that strontium isotope ratios in preserved tissues reflect the ratios in the diet, which in turn reflect the ratios present in the surface geology underlying the lowest component of the food chain (Bentley et al. 2002; Ericson 1985; Price et al. 1994, 2002). Pronghorn strontium isotope ratios are therefore informative of the geographic region from which a pronghorn's food and water was derived. Modern Wyoming pronghorn groups show a fairly wide range of geographic variation, reflecting the area's diverse geology (Fenner 2007).

Pronghorn groups shift in both size and composition over the course of a year (Byers 2003; O'Gara 2004). During the fall mating season, bucks attempt to gather does into harems, which must be defended from the advances of other bucks. Does will often leave a harem to join that of a more desirable buck. Following mating season, does and bucks gather into large groups, sometimes including hundreds of individuals. By late May, these groups will have broken up and pregnant does will find isolated locations to give birth to twins. After birthing season, pronghorn often re-gather into small groups or "bachelor herds" of only a few individuals. Pronghorn groups thus merge and shift both seasonally and reproductively, and it is difficult to define what is meant by a "pronghorn herd" over the course of a year. However, pronghorn typically have relatively small home ranges, averaging less than 70 square kilometers (O'Gara 2004:170). Some pronghorn migrate seasonally, but usually return to the same ranges. For example, Hoskinson and Tester (1980) found that all 22 radio-collared pronghorn in Idaho returned to the same range in consecutive summers. It may be that home range consistency is related to the need to know dominance relations, which for does are largely established at birth (Byers 1997:102-118). In any case, while the composition of a particular group may vary, pronghorn within a particular large 
area tend to remain or return there. Hunt areas in Wyoming covering hundreds of square kilometers include multiple entire home ranges, but for the purposes of this study are treated as containing a single pronghorn population. This may overestimate the isotopic variation within a true modern "herd," but will minimize the chance of false positive (multiple kill) findings. A low percentage of modern pronghorn in southwestern Wyoming undergo long-range seasonal migrations that (if performed during enamel formation) could affect enamel isotope ratios. More importantly for the current analysis, the potential for congregation of multiple populations during migration must be considered when applying the technique to archaeological sites.

Pronghorn roam wild in Wyoming, but that does not mean they are unaffected by humans. They are managed as a game animal, and pronghorn population size in Wyoming has fluctuated with hunting pressure as well as weather and nonhuman predator pressure. Unlike deer, pronghorn avoid jumping over fences (although they often are able to pass under wire-strand fences) and therefore are somewhat restricted in their movements in developed areas of the state (Karhu and Anderson 2006; Yoakum 2004b). Interstate highways, particularly I-80 in southern Wyoming, also restrict their movements. Nevertheless, pronghorn are clearly wild. They are not routinely provisioned, and isotopic differences among modern hunt areas should reflect true environmental or behavioral differences rather than management differences.

Isotope ratio analysis will only produce evidence of accumulation when the multiple prey populations represented within the accumulation have substantially different mean isotope ratios for at least one element. This requires spatial or temporal variation in the climatic, geologic, or behavioral conditions that control prey isotopic composition. Analysis of modern pronghorn shows substantial variation across Wyoming for all three elements under consideration (Table 2; see also maps in Fenner 2007; Fenner and Frost 2009). This was expected because Wyoming's varied topography and geologic history produces a wide range of climatic and geologic conditions across the state (Knight 1994). Areas with more uniform environmental and geologic conditions, such as portions of the Great Plains, may not produce sufficient iso- topic variation to distinguish accumulations from single-population kills.

While analysis of modern prey populations may adequately model spatial variation, temporally based isotopic variation is more difficult to predict. Climatic models may suggest changing environmental conditions that would be expected to produce differing mean carbon or oxygen isotope ratios, but rarely provide adequate temporal resolution to predict the isotopic variation potential of a single bonebed. Note, however, that regardless of whether isotopic variation within a bonebed is ultimately derived from spatial or temporal variation, if it substantially exceeds the variation expected within a population existing at a single place and time, then the bonebed likely results from an accumulation of multiple populations.

For certain prey animal species, including pronghorn, it is possible that a multiple-population accumulation was the result of a single interception of populations that had temporarily aggregated while migrating rather than being the result of multiple kill events. Isotopic analysis alone may not be able to distinguish between these two circumstances. This is particularly a concern for the Trappers Point site, which is located at a modern pronghorn migration bottleneck.

\section{Samples}

The modern comparative sample is a collection of male pronghorn first incisors obtained from hunters by the Wyoming Game and Fish Department (WGFD) during late September and early October of 2004 and 2005 as part of a separate study. The data collected by WGFD included the hunt area in which each pronghorn was killed. Wyoming hunt areas vary in size and terrain. Some hunt area boundaries are natural formations such as mountain ranges or rivers while other boundaries are artificial constructions such as highways. Tooth cementum-based age determination performed by WGFD shows that the sample has an average age of $4.7 \pm 1.9$ years, with a range of 1.5 to 10.5 years. Sample size varies by hunt area, ranging from one to 24 samples (Table 2).

Six archaeological sites in southwestern Wyoming that contain substantial pronghorn bonebeds are included in the analysis (Table 1). In addition, a virtual site is modeled using random 
Table 1. Archaeological Sites Analyzed.

\begin{tabular}{|c|c|c|c|c|c|}
\hline Site Name & $\begin{array}{c}\text { Site } \\
\text { Identifier }\end{array}$ & $\begin{array}{c}\text { Approximate } \\
\text { Age }\end{array}$ & $\begin{array}{c}\text { Pronghorn } \\
\text { MNI }\end{array}$ & $\begin{array}{c}\text { Pronghorn } \\
\text { NISP }\end{array}$ & $\begin{array}{l}\text { Hunt } \\
\text { Area }\end{array}$ \\
\hline Austin Wash & 48UT390 & $1197 \mathrm{BP}$ & 18 & 1880 & 94 \\
\hline Boars Tusk & 48 SW1373 & Historic Period & 9 & 717 & 92 \\
\hline Eden-Farson & 48SW304 & Historic Period & $>226$ & & 92 \\
\hline Firehole Basin & 48SW1217 & $630 \mathrm{BP}$ & 26 & 433 & 59 \\
\hline Gailiun & 48SU1156 & $150 \mathrm{BP}$ & 8 & & 91 \\
\hline Trappers Point & 48SU1006 & 6010 to $5160 \mathrm{BP}$ & 27 & 1683 & 88 \\
\hline
\end{tabular}

The Trappers Point component of interest is Stratum V.

Sources: Eckles 1999; Fisher and Frison 2000; Lubinski 1997; Middleton et al. 2007; Miller et al. 1999a; Schroedl 1985.

Blanks indicate that NISP data is not currently available for Eden-Farson or Gailiun.

samples from modern hunt areas (see Methods section for more information). Finally, the Reiser Canyon natural mass die-off site is included for comparative purposes. In 1991, about 150 pronghorn died after falling over a cliff in Reiser Canyon, which is located near the southern edge of Hunt Area 96 (Lubinski and O'Brien 2001; Ottman 1992). Pronghorn sex was not recorded during collection of the Reiser Canyon sample, but presumably includes a mix of males and females. Comparing the all-male hunt area samples to presumably mixed-sex samples from Reiser Canyon and archaeological sites introduces uncertainty, particularly since there is some evidence that, during summer, female pronghorn range over a larger area than do males (Hoskinson and Tester 1980; Reynolds 1984). However, males and females are together in mixed groups most of the year, and probably consume similar isotopic regimes.

Tooth enamel was used in all reported isotope analyses due to concerns with potential diagenetic contributions to isotopic variability in bone samples. All teeth selected for isotope analysis are incisors. Incisors have tapered root structures that allow them to easily slip out of their mandibular sockets following post-mortem tissue degeneration, and therefore incisors are commonly found loose in archaeological contexts rather than embedded in bone. It is often difficult to assign side and tooth number to loose pronghorn incisors, so there is a possibility that more than one tooth from an individual may be included in archaeological samples. Every attempt was made to obtain teeth from separate individuals by comparing overall size, wear amount and intra-site location (cf. Klein and Cruz-Uribe 1984:26-27). If two teeth from an individual nevertheless are included, the resulting isotopic variation within the archaeological site would likely be less than otherwise would be the case. This favors the position of not identifying a site as highly variable and therefore not likely the result of an accumulation from multiple populations.

\section{Methods}

Prior to isotope ratio analysis, each sample underwent a pretreatment procedure intended to remove organics and other adhering materials. Each tooth was mechanically cleaned, then enamel was collected by using a Dremel drill to carve a groove along the length of the buccal enamel surface of the tooth. Enamel development proceeds from the occlusal surface to the cervix (Hillson 1986:114), so sampling along the tooth length provides an isotopic ratio that averages the entire period of enamel formation (excluding any loss due to tooth wear during life). This reduces the influence of shortterm isotope ratio variations due to seasonal fluctuations or nursing by fawns. Using the procedure described by Koch et al. (1998:125; see also Koch et al. 1997), the enamel was then soaked in bleach followed by $.1 \mathrm{~N}$ acetic acid. Koch et al.'s procedure was modified slightly by reducing soak time in response to Garvie-Lok et al.'s (2004) work that showed long soak times may cause substantial sample loss and possible isotopic inaccuracy due to recrystallization. Details of the pretreatment procedure are provided elsewhere (Fenner 2007).

Carbon and oxygen isotope ratios in enamel carbonate were measured using continuous-flow isotope ratio mass spectrometry at the University of Wyoming Stable Isotope Facility and are reported in parts per mil (\%o) with respect to the V-PDB standard. For compatibility with archaeological analyses, $1.51 \%$ is added to modern carbon isotope ratios to account for the modern carbon ratio offset, which 
Table 2. Hunt Area Isotopic and Environment Data.

\begin{tabular}{|c|c|c|c|c|c|c|c|c|c|c|c|c|c|}
\hline $\begin{array}{l}\text { Hunt } \\
\text { Area } \\
\end{array}$ & $\begin{array}{c}\delta^{13} \mathrm{C} \\
n \\
\end{array}$ & $\begin{array}{l}\delta^{13} \mathrm{C} \\
\text { Mean } \\
\end{array}$ & $\begin{array}{l}\delta^{13} \mathrm{C} \\
\text { Std } \\
\text { Dev }\end{array}$ & $\begin{array}{c}\delta^{18} \mathrm{O} \\
n \\
\end{array}$ & $\begin{array}{l}\delta^{18} \mathrm{O} \\
\text { Mean } \\
\end{array}$ & $\begin{array}{c}\delta^{18} \mathrm{O} \\
\text { Std } \\
\text { Dev } \\
\end{array}$ & $\begin{array}{c}{ }^{87} \mathrm{Sr} /{ }^{86} \mathrm{Sr} \\
n \\
\end{array}$ & $\begin{array}{c}{ }^{87} \mathrm{Sr} /{ }^{86} \mathrm{Sr} \\
\text { Mean }\end{array}$ & $\begin{array}{l}{ }^{87} \mathrm{Sr} /{ }^{86} \mathrm{Sr} \\
\text { Std Dev }\end{array}$ & $\begin{array}{c}\text { Mean } \\
\text { May-Oct } \\
\text { Temp. }\end{array}$ & $\begin{array}{c}\text { Mean } \\
\text { Annual } \\
\text { Temp. }\end{array}$ & $\begin{array}{c}\text { Mean } \\
\text { May-Oct } \\
\text { RH } \\
\end{array}$ & $\begin{array}{c}\text { Mean } \\
\text { Annual } \\
\text { RH } \\
\end{array}$ \\
\hline 17 & 2 & -11.74 & .66 & 2 & -9.01 & 1.35 & & & & 15.5 & 6.9 & 53.5 & 58.6 \\
\hline 19 & 3 & -11.98 & .33 & 3 & -9.96 & 1.08 & & & & 15.5 & 7.0 & 54.4 & 59.8 \\
\hline 23 & 7 & -11.55 & .45 & 6 & -10.01 & .47 & & & & 15.1 & 6.8 & 51.4 & 57.0 \\
\hline 24 & 8 & -11.35 & .60 & 8 & -8.27 & 1.17 & & & & 15.3 & 7.0 & 52.6 & 57.8 \\
\hline 32 & 1 & -11.06 & & 1 & -9.78 & & & & & 14.4 & 6.5 & 50.0 & 55.6 \\
\hline 42 & 13 & -11.07 & .45 & 13 & -5.96 & 1.36 & & & & 13.1 & 5.6 & 50.1 & 53.8 \\
\hline 43 & 1 & -10.91 & & 1 & -8.36 & & & & & 12.6 & 5.2 & 49.0 & 51.8 \\
\hline 46 & 4 & -10.81 & .65 & 4 & -6.98 & .44 & & & & 12.9 & 5.6 & 48.5 & 54.8 \\
\hline 47 & 16 & -10.83 & .40 & 17 & -6.81 & 1.20 & 2 & .71153 & .00140 & 12.9 & 5.3 & 49.4 & 55.9 \\
\hline 53 & 16 & -10.99 & .51 & 17 & -7.01 & 1.71 & & & & 13.5 & 5.7 & 52.1 & 59.3 \\
\hline 57 & 12 & -10.34 & .81 & 12 & -2.81 & 1.18 & 3 & .71234 & .00071 & 13.4 & 5.6 & 47.0 & 56.6 \\
\hline 59 & 3 & -11.01 & .65 & 3 & -6.05 & 1.12 & 3 & .71200 & .00153 & 13.4 & 5.5 & 45.5 & 55.7 \\
\hline 61 & 1 & -10.06 & & 1 & -7.04 & & & & & 13.6 & 5.6 & 48.3 & 58.0 \\
\hline 64 & 1 & -11.64 & & 1 & -7.36 & & & & & 12.8 & 4.8 & 46.7 & 55.9 \\
\hline 65 & 2 & -10.82 & .49 & 2 & -5.43 & .53 & & & & 10.4 & 3.0 & 48.7 & 54.6 \\
\hline 66 & 4 & -11.21 & .65 & 4 & -7.44 & 1.05 & & & & 15.0 & 6.6 & 45.0 & 52.2 \\
\hline 75 & 1 & -11.53 & & 1 & -7.21 & & & & & 14.6 & 6.3 & 47.1 & 53.8 \\
\hline 87 & 8 & -10.56 & .53 & 8 & -8.34 & 1.78 & 7 & .71200 & .00090 & 7.2 & -.4 & 47.7 & 52.8 \\
\hline 88 & 9 & -10.55 & .87 & 9 & -7.92 & 2.21 & 8 & .71114 & .00064 & 8.7 & 1.1 & 42.9 & 49.2 \\
\hline 89 & 10 & -10.28 & .75 & 9 & -6.98 & 1.22 & 9 & .71086 & .00041 & 8.9 & 1.2 & 42.1 & 49.3 \\
\hline 90 & 10 & -10.17 & .90 & 10 & -5.90 & 1.05 & 3 & .71209 & .00098 & 10.4 & 2.2 & 43.3 & 50.5 \\
\hline 91 & 24 & -10.37 & .68 & 24 & -8.31 & 2.46 & 10 & .71278 & .00072 & 10.7 & 2.4 & 45.2 & 53.4 \\
\hline 92 & 17 & -10.18 & .66 & 17 & -7.59 & 1.59 & 10 & .71381 & .00129 & 12.4 & 4.1 & 44.0 & 53.8 \\
\hline 93 & 4 & -9.47 & .86 & 4 & -4.55 & 3.31 & 3 & .71041 & .00017 & 11.1 & 3.0 & 42.0 & 50.4 \\
\hline 94 & 1 & -9.31 & & 1 & -4.98 & & 1 & .71037 & & 12.8 & 4.6 & 42.3 & 51.4 \\
\hline 95 & 3 & -10.45 & .33 & 3 & -3.92 & 1.54 & 3 & .71008 & .00013 & 13.9 & 6.0 & 42.9 & 51.9 \\
\hline 96 & 10 & -10.09 & .99 & 10 & -6.32 & 2.27 & 4 & .71121 & .00013 & 12.8 & 4.2 & 42.5 & 51.3 \\
\hline 106 & 2 & -10.99 & .61 & 2 & -7.36 & 1.41 & & & & 14.1 & 6.1 & 47.8 & 56.0 \\
\hline 107 & 6 & -10.68 & .54 & 6 & -7.85 & .91 & 4 & .71581 & .00114 & 10.3 & 2.3 & 46.4 & 54.1 \\
\hline 112 & 1 & -10.12 & & 1 & -5.92 & & 1 & .71176 & & 13.1 & 5.4 & 46.0 & 55.3 \\
\hline 115 & 4 & -11.07 & .66 & 4 & -7.29 & 1.12 & 1 & .71006 & & 13.4 & 5.7 & 49.3 & 55.0 \\
\hline
\end{tabular}

Outliers excluded. $\delta^{13} \mathrm{C}$ mean values increased by $+1.51 \%$ to account for modern carbon offset. $\delta^{13} \mathrm{C}$ and $\delta^{18} \mathrm{O}$ values are per-mil VPDB. Blank indicates no measured values, or insufficient samples to compute standard deviation. $n$ : number of samples; Temp.: temperature in C; RH: relative humidity in \%. Temp. and RH means computed by averaging raster pixel values within hunt area after eliminating areas above $2800 \mathrm{~m}$ elevation; raster data provided by Spatial Climate Analysis Service at Oregon State University and Climate Source Inc.

is likely produced by a recent change in atmospheric $\mathrm{CO}_{2}$ composition due to the burning of fossil fuels (Tieszen and Fagre 1993). Strontium isotope ratios were measured using thermal ionization mass spectrometry (TIMS) at the University of Wyoming Isotope Geology Laboratory. Prior to TIMS analysis, enamel strontium was separated from other elements (notably rubidium, which overlaps with strontium at mass 87 ) using a strontium-specific cation exchange resin. The strontium separation procedure is described in detail in Fenner (2007). Due to this lengthy process, fewer teeth were processed for strontium isotope ratios $(n=107)$ than was the case for carbon $(n=$
$268)$ and oxygen $(n=267)$ ratios. Results are reported as unitless ${ }^{87} \mathrm{Sr} /{ }^{86} \mathrm{Sr}$ ratios. Twelve NIST987 strontium standards were run, with measured values averaging $.71026 \pm .00001$. This indicates that strontium measurement uncertainty is within the fifth decimal place. Intra-individual variation was $.17 \pm .14 \%$ o for carbon, $.61 \pm .33 \%$ o for oxygen, and $.00003 \pm .00004$ for strontium.

Post-depositional alteration of the chemical properties of a sample is always a concern when analyzing isotope ratios from archaeological sites, and has received much research attention (for reviews of this work, see Hedges 2002; Hoppe et al. 2003; Kohn and Cerling 2002; Lee-Thorp and 


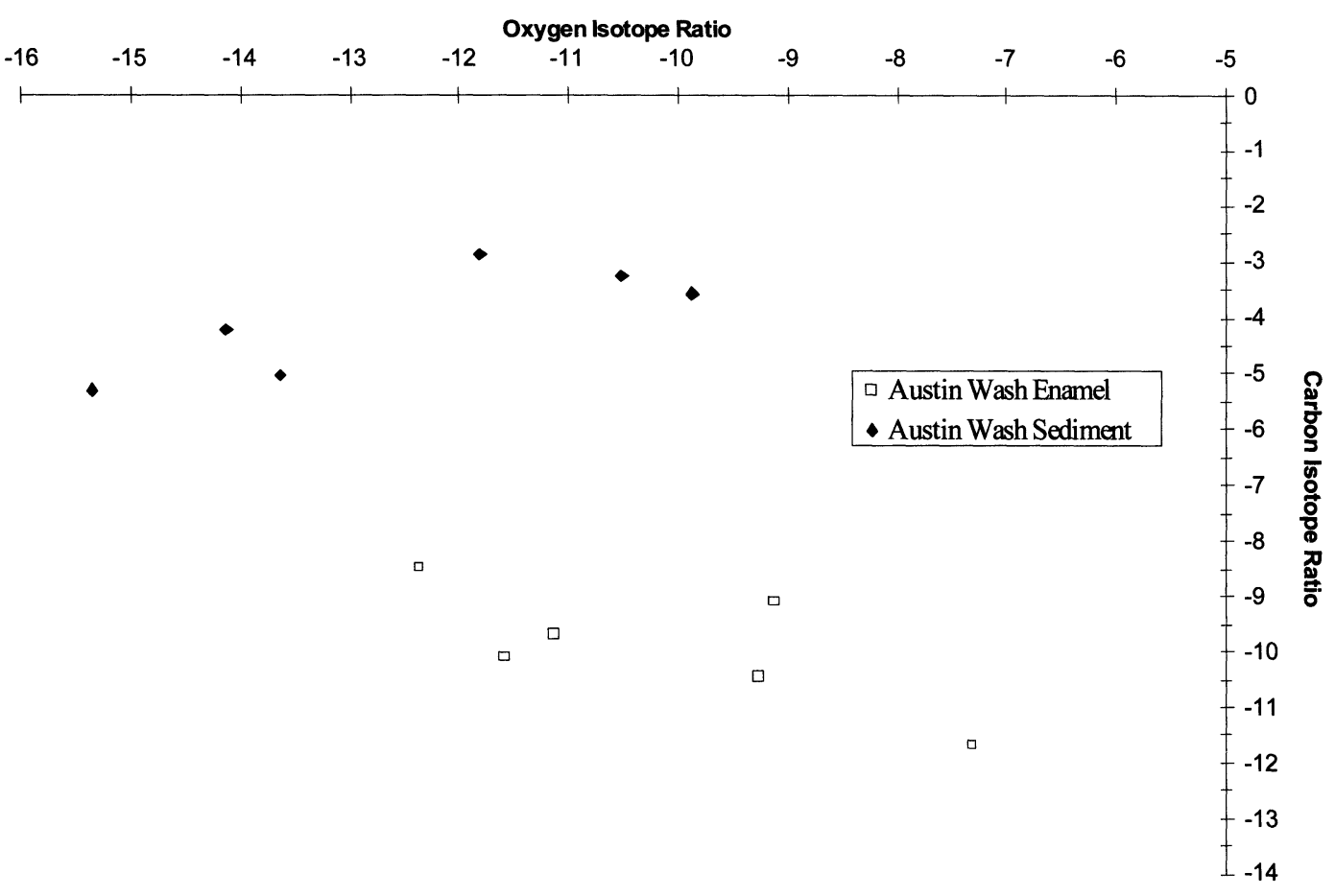

Figure 6. Carbon and oxygen isotope ratios of sediment (filled diamonds) and pronghorn enamel (empty squares) from Austin Wash (48UT390). Oxygen isotope ratio is $\delta^{18} \mathrm{O}$ (per mil); carbon isotope ratio is $\delta^{13} \mathrm{C}$ (per mil).

Sponheimer 2003). The current consensus is that the non-porous, crystalline structure of enamel protects its hydroxyapatite from significant diagenesis in most situations, even over millions of years (e.g., Hodell et al. 2004; Knudson et al. 2004; LeeThorp and Sponheimer 2006). A qualitative check for diagenesis was performed by comparing the isotope ratios in pronghorn enamel from the Austin Wash site to the ratios contained in the surrounding sediment carbonate. The carbon and oxygen isotope ratios in carbonate from six sediment samples saved from the 1981 Austin Wash excavation were measured and compared to the ratios in enamel from the site. The ratios in the sediment are distinct from the ratios in the enamel (Figure 6), and therefore diagenetic alteration of isotopic composition is not indicated.

\section{Statistical Techniques}

The statistical approach used in this study is essentially the same as is described in detail in Fenner (2008; see also Fenner 2007:59-62). Isotope ratio values lying more than 1.5 times the interquartile range below the first quartile or above the third quartile are considered outliers and removed from further consideration. While this criterion is somewhat arbitrary, it is a commonly applied rule of thumb for identifying suspected outliers (Moore and McCabe 1999:47). As a result, out of a total of 667 measurements from 276 individuals, 13 measurements (1.9 percent) were discarded. For multielement analyses, all isotope values for these 12 individuals have been excluded. Basic descriptive statistics were then computed for the remaining samples.

Standard deviation was used as the basic measure of spread or variability for each group and isotope ratio. Each group's isotope ratio values were centered about the origin, and multiplied by an element-specific scaling factor so that all isotope ratios use comparable scales. The three scaled isotope ratios for each individual were then combined into a three-dimensional Euclidean distance, and these distances used to assess variability within and among groups. Some hunt areas lack measured strontium ratio samples but include sufficient carbon and oxygen samples for comparison with archaeological sites, so two-dimensional carbon- 
Table 3. Archaeological Site Summary Isotope Results.

\begin{tabular}{|c|c|c|c|c|c|c|c|c|c|}
\hline \multirow[b]{2}{*}{ Site } & \multicolumn{3}{|c|}{$\delta^{13} \mathrm{C}(\% \circ$ VPDB $)$} & \multicolumn{3}{|c|}{$\delta^{18} \mathrm{O}(\% \circ \mathrm{VPDB})$} & \multicolumn{3}{|c|}{${ }^{87} \mathrm{Sr} /{ }^{86} \mathrm{Sr}$} \\
\hline & $n$ & Mean & Std Dev & $n$ & Mean & Std Dev & $n$ & Mean & Std Dev \\
\hline Austin Wash & 7 & -10.15 & 1.20 & 6 & -9.90 & 1.84 & 6 & .71065 & .00006 \\
\hline Boars Tusk & 6 & -11.51 & .72 & 6 & -9.10 & .84 & 6 & .71190 & .00047 \\
\hline Eden-Farson & 12 & -8.84 & 1.00 & 12 & -10.54 & 1.78 & 7 & .71175 & .00061 \\
\hline Firehole Basin & 7 & -8.65 & .69 & 8 & -12.60 & 2.37 & 7 & .71196 & .00098 \\
\hline Gailiun & 8 & -9.19 & .76 & 8 & -9.83 & 1.47 & 7 & .71176 & .00053 \\
\hline Trappers Point & 19 & -10.02 & 1.05 & 19 & -9.04 & 2.06 & 6 & .71290 & .00034 \\
\hline
\end{tabular}

Outliers excluded. $n=$ Number of Samples.

oxygen Euclidean distance values are also reported.

This study also investigates the isotopic variability among groups through non-parametric bootstrapping (see Buntinas and Funk [2005:471-502] for general discussion regarding such techniques). Non-parametric bootstrapping, sometimes referred to as resampling, can provide an estimate of the probability that a sample of a certain size drawn from a population would be at least as variable as a given amount. When applied to this project, the population data are isotopic distance values for a particular modern hunt area. A subsample of a certain size is randomly selected from this group and the standard deviation of distance values for that group is computed. This subsampling process is repeated 1,000 times for each hunt area. The standard deviation of isotope distances obtained from a specific archaeological site of interest is then compared to the list of 1,000 subsample standard deviation values for each hunt area, and the number of modern subsamples whose variability is less than that of the archaeological site of interest is determined. This number, when divided by 1,000 , is interpreted as the probability that the archaeological site is more variable than the modern hunt area. An Excel-based Visual Basic program for performing these computations is available from the author.

Another aspect of the investigation was modeling a virtual site for comparison to archaeological sites. To create the virtual site, one instance of a virtual pronghorn group is created by randomly selecting a pronghorn subsample from among all modern hunt area pronghorn, and the individual isotope distances computed. The standard deviation of this group of pronghorn distances is then calculated, and this process repeated a total of 20,000 times. The average of the group isotopic distance standard deviations is then used as an estimate of the standard deviation of a virtual site accumulated from the parent population. That is, it represents the amount of geographically based variability one would expect if the modeled site had been accumulated from all hunt areas (spanning the entire state, though most samples are from southwestern Wyoming) rather than as a mass kill of a single hunt area group. This virtual site can be thought of as representing an average random geographic accumulation from a very wide area. As such, it would be expected to be more variable than any single modern hunt area. Because the virtual site is an averaged value, an archaeological site that was in fact accumulated from multiple populations may have somewhat less variability than the virtual site. The relative magnitude of virtual site and archaeological site variability will therefore be used as a meaningful but not conclusive indicator when assessing the significance of isotope variability, along with comparisons to modern hunt area and Reiser Canyon sample variability.

\section{Results}

After removing outliers, isotope ratio summary descriptive data were calculated for each archaeological site (Table 3). Interestingly, there is no significant correlation between isotope ratios for any two elements (Kendall's $\rho$, all $p>.09$ ). This is somewhat surprising, since both $\delta^{13} \mathrm{C}$ and $\delta^{18} \mathrm{O}$ are driven to some degree by climate. The lack of significant correlation may be the result of microclimate differences among the areas inhabited by pronghorn during enamel formation or, more likely, is simply an artifact of small sample size and a weak true correlation. Analysis of element isotope ratio correlations among modern hunt areas supports the latter hypothesis; there is no significant correlation between $\delta^{13} \mathrm{C}$ and $\delta^{18} \mathrm{O}$ using pronghorn from six hunt areas in southwestern Wyoming 
Table 4. Archaeological Site and Hunt Area Means Comparisons.

\begin{tabular}{|c|c|c|c|c|c|c|c|c|c|c|}
\hline \multirow[b]{2}{*}{ Arch. Site } & \multirow{2}{*}{$\begin{array}{l}\text { Hunt } \\
\text { Area }\end{array}$} & \multicolumn{3}{|c|}{$\delta^{13} \mathrm{C}$} & \multicolumn{3}{|c|}{$\delta^{18} \mathrm{O}$} & \multicolumn{3}{|c|}{${ }^{87} \mathrm{Sr} /{ }^{86} \mathrm{Sr}$} \\
\hline & & $N$ & $t$ & Sig. & $N$ & $t$ & Sig. & $N$ & $t$ & Sig. \\
\hline Boars Tusk & 92 & 6,17 & -3.994 & .00 & 6,17 & -2.923 & .01 & 6,10 & -4.26 & .00 \\
\hline Eden-Farson & 92 & 12,17 & 4.031 & .00 & 12,17 & -4.572 & .00 & 7,10 & -4.41 & .01 \\
\hline Firehole Basin & 59 & 7,3 & 5.159 & .01 & 8,3 & -6.202 & .00 & 7,3 & -.03 & .98 \\
\hline Gailiun & 91 & 8,24 & 3.944 & .00 & 8,24 & -2.095 & .05 & 7,10 & -3.67 & .00 \\
\hline Trappers Point & 87 & 17,8 & 1.702 & .10 & 17,8 & -.863 & .40 & 6,8 & 6.67 & .00 \\
\hline Trappers Point & 88 & 17,9 & 1.368 & .19 & 17,9 & -1.259 & .23 & 6,7 & 2.46 & .04 \\
\hline
\end{tabular}

The hunt area containing the Austin Wash site has only one sample and could not be included in means comparisons. Modern $\delta^{13} \mathrm{C}$ values increased by $1.51 \%$ prior to means comparison to account for modern carbon offset. Trappers Point is close to the border between Hunt Areas 87 and 88 so both were tested. N: Number of site samples, number of hunt area samples. $t$ : independent samples t-test, equal variances not assumed. Sig.: Two-tailed significance probability; bold typeface indicates statistical significance at $\alpha=.05$. Non-parametric Mann-Whitney U tests provide essentially the same results, except the Gailiun/HA $91 \delta^{18} \mathrm{O}$ means are not significantly different $(p=.17)$.

(Kendall's $\rho, p=.53, n=6$ ) even though the larger state-wide sample of modern hunt areas shows a significant though not particularly strong correlation (Kendall's $\rho=.42, p<.01, n=22$ ).

The mean isotope ratios from most archaeological sites do not closely match the ratios of their modern hunt areas (Table 4). For carbon and oxygen isotopes, this could be related to climatic changes; for instance, colder conditions during the Little Ice Age could have caused more depleted mean oxygen isotope values at the Eden-Farson site. Changes in mean environmental aridity also likely contribute to prehistoric-to-modern differences, particularly for carbon isotopes. Strontium differences perhaps indicate prehistoric pronghorn migration or human prey transport behavior. The implications of these mean differences will be further discussed in the individual archaeological site discussion sections.

As discussed in the Methods section, individual site and hunt area isotope ratios were scaled and converted to three- and two-dimensional distances. The standard deviation of each group's carbonoxygen-strontium distances was then computed (Table 5, Figure 7). The two-dimensional carbonoxygen distance standard deviations, for which a larger sample is available, were also calculated (Figure 8). These standard deviations of hunt area isotopic distances measure the amount of pronghorn isotopic variability within each area. An archaeological site isotopic distance standard deviation that substantially exceeds modern hunt area distance standard deviation values indicates that the site was formed through accumulation of pronghorn from multiple temporal or spatial populations.
(More quantitative assessments of comparative variation produced using bootstrap analysis are provided for individual sites in the Discussion section.) The virtual site in Figure 7 was derived from random selection of pronghorn from all modern hunt areas, and serves as an indicator of a level of variation to be expected in an accumulated site. The Reiser Canyon site, which was formed by a modern mass pronghorn die-off, serves as an indicator of the level of variation to expect in a mass kill situation, as do modern hunt areas.

\section{Discussion}

The distance metrics show some interesting patterns among archaeological sites (Figure 7 and Figure 8). Austin Wash and Trappers Point show the most variation among archaeological sites in both the three-dimensional and two-dimensional distances. The variation at each of these sites is similar to or greater than that of the virtual site, which was assembled as an example of a geographically based accumulation site, and substantially exceeds that of Reiser Canyon and most hunt areas, which are considered single-population assemblages. On the other hand, the Gailiun, Firehole Basin, and Boars Tusk sites show relatively little variation, while the Eden-Farson site is intermediate between the two groups. Overall, Figure 7 and Figure 8 indicate that Austin Wash and Trappers Point are likely to be accumulations from multiple populations, Gailiun, Firehole Basin, and Boars Tusk show little evidence of multiple-population accumulation, and Eden-Farson shows weak support for accumulation from multiple populations. 
Table 5. Scaled Isotope Distance Measures.

\begin{tabular}{|c|c|c|c|c|c|c|}
\hline \multirow[b]{2}{*}{ Location } & \multicolumn{3}{|c|}{ Combined $\delta^{13} \mathrm{C}, \delta^{18} \mathrm{O}$ and ${ }^{87} \mathrm{Sr} /{ }^{86} \mathrm{Sr}$} & \multicolumn{3}{|c|}{ Combined $\delta^{13} \mathrm{C}$ and $\delta^{18} \mathrm{O}$} \\
\hline & $N$ & $\begin{array}{l}\text { Average } \\
\text { Distance }\end{array}$ & $\begin{array}{c}\text { Standard } \\
\text { Deviation }\end{array}$ & $N$ & $\begin{array}{l}\text { Average } \\
\text { Distance }\end{array}$ & $\begin{array}{l}\text { Standard } \\
\text { Deviation }\end{array}$ \\
\hline \multicolumn{7}{|l|}{ Modern } \\
\hline Hunt Area 19 & & & & 3 & 1.03 & .59 \\
\hline Hunt Area 23 & & & & 6 & 1.18 & .52 \\
\hline Hunt Area 24 & & & & 8 & 1.72 & .81 \\
\hline Hunt Area 42 & & & & 13 & 1.67 & .58 \\
\hline Hunt Area 46 & & & & 4 & 1.48 & .62 \\
\hline Hunt Area 47 & & & & 15 & 1.47 & .61 \\
\hline Hunt Area 53 & & & & 16 & 2.02 & .80 \\
\hline Hunt Area 57 & 3 & 1.69 & .26 & 12 & 2.14 & 1.12 \\
\hline Hunt Area 59 & 3 & 2.68 & 1.31 & 3 & 1.60 & .72 \\
\hline Hunt Area 66 & & & & 4 & 1.61 & .85 \\
\hline Hunt Area 87 & 7 & 2.62 & .89 & 8 & 1.95 & .95 \\
\hline Hunt Area 88 & 8 & 3.24 & 1.18 & 9 & 2.74 & 1.43 \\
\hline Hunt Area 89 & 8 & 2.07 & 1.11 & 9 & 2.18 & 1.21 \\
\hline Hunt Area 90 & 3 & 3.87 & 1.33 & 10 & 2.17 & 1.36 \\
\hline Hunt Area 91 & 10 & 2.87 & 1.12 & 24 & 2.54 & 1.13 \\
\hline Hunt Area 92 & 10 & 3.06 & 1.00 & 17 & 2.12 & .99 \\
\hline Hunt Area 93 & 3 & 2.84 & 2.31 & 4 & 3.06 & 1.95 \\
\hline Hunt Area 95 & 3 & 1.39 & .58 & 3 & 1.38 & .57 \\
\hline Hunt Area 96 & 4 & 2.01 & 1.08 & 10 & 2.92 & 1.71 \\
\hline Hunt Area 107 & 4 & 2.29 & .68 & 6 & 1.43 & .71 \\
\hline Hunt Area 115 & & & & 4 & 1.72 & .67 \\
\hline Reiser Canyon & 9 & 3.12 & .76 & 15 & 2.90 & 1.18 \\
\hline Virtual Site & 7 & N/A & 1.38 & 7 & N/A & 1.25 \\
\hline \multicolumn{7}{|l|}{ Archaeological } \\
\hline Austin Wash & 5 & 2.46 & 1.52 & 7 & 3.09 & 1.67 \\
\hline Boars Tusk & 4 & 1.60 & .97 & 5 & 1.82 & 1.11 \\
\hline Eden-Farson & 6 & 2.94 & 1.23 & 12 & 2.88 & 1.23 \\
\hline Firehole Basin & 7 & 2.69 & .89 & 7 & 2.04 & 1.00 \\
\hline Gailiun & 7 & 2.00 & .92 & 8 & 2.06 & 1.22 \\
\hline Trappers Point & 6 & 2.45 & 1.37 & 17 & 2.83 & 1.95 \\
\hline
\end{tabular}

The standard deviation columns contain the key variability measures. $N$ : Number of samples. For the virtual site, $N$ is the number of subsamples per iteration.

This overall assessment must be evaluated in full context before assigning a particular formation history to a site. This includes consideration of nonisotopic formation evidence (Table 6) and a quantitative assessment of relative isotope variation. The remainder of this section reviews the overall site formation evidence based on isotopic data as well as traditional analyses of each of the six archaeological pronghorn bonebed sites included in this study.

\section{Austin Wash}

As noted previously, the carbon-oxygen-strontium and carbon-oxygen results (Figure 7 and Figure 8) seem to support the designation of Austin Wash as a multiple-population accumulation rather than a mass kill. This can be investigated more quantitatively using bootstrap analysis. Note that both carbon-oxygen-strontium distances and carbonoxygen distances at Austin Wash are more variable than at least 90 percent of subsamples from Reiser Canyon and all hunt areas (Table 7). In addition, in every instance Austin Wash is more variable than is the virtual site, which of course is known to be based on an accumulation from multiple populations. It appears therefore that Austin Wash is an accumulation of multiple populations rather than the result of a single mass kill. This is in agreement with Lubinski's (1997) analysis, though not with Schroedl's (1985) initial assessment.

At this point, it may be informative to consider Austin Wash's isotope values in the context of sur- 


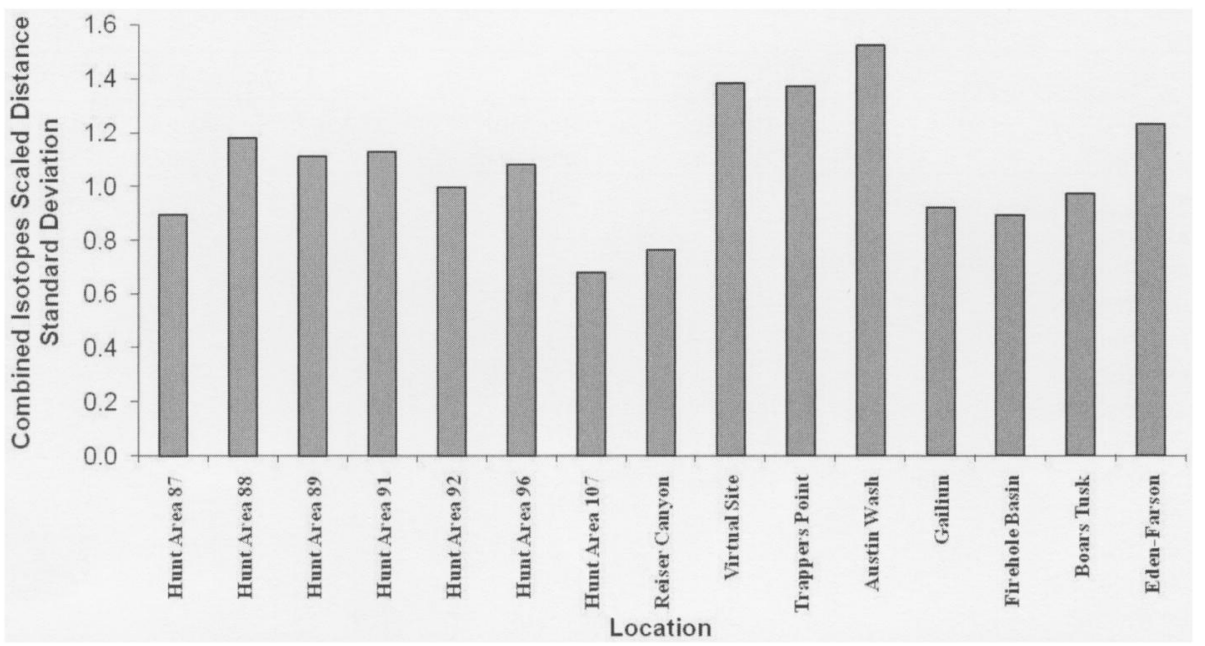

Figure 7. Comparison of carbon-oxygen-strontium scaled distance metric variation for modern hunt areas, the Reiser Canyon sample, a virtual site, and six archaeological sites. Minimum four samples per hunt area.

rounding hunt area isotope values. Austin Wash lies within modern Hunt Area 94, for which there is unfortunately only a single modern sample available. It is not far from Hunt Area 95, which has three modern samples available. These two hunt areas produced very similar strontium isotope ratios that are just slightly lower than the mean Austin Wash strontium isotope ratio. While the small sample sizes involved make it difficult to reach firm conclusions, the strontium isotope ratios suggest that the multiple populations included within Austin Wash did not come from nonlocal geographic areas. Instead, it is more likely that the populations were temporally, rather than geographically, separate.

\section{Firehole Basin \#11}

As was the case for Austin Wash, comparative analysis of Firehole Basin isotope variability (Figure 7 and Figure 8) supports Lubinski's assessment. Firehole Basin has the least overall variability of any of the archaeological sites. More importantly, it is less variable than six of seven hunt areas for the carbon-oxygen-strontium distance metric and less variable than Reiser Canyon for the carbonoxygen distance metric. Quantitative assessment of these relative differences further illustrates this pattern (Table 7). In every case and by wide margins, Firehole Basin is less variable than the virtual site. It is less variable than more than half of subsamples from two other hunt areas, and almost forty percent of subsamples from another. Using carbonoxygen-strontium distances, Firehole Basin is less variable than more than half of Hunt Area 91 and 92 subsamples. None of these measures indicate

Table 6. Assessments of Evidence for Multiple Pronghorn Populations within Bonebeds.

\begin{tabular}{|c|c|c|c|c|c|c|c|}
\hline$\underline{\text { Site }}$ & $\begin{array}{l}\text { Radio- } \\
\text { carbon }\end{array}$ & PS & PD & $\begin{array}{c}\text { Lubinski } \\
\text { Overall } \\
\text { Assessment }\end{array}$ & Other Types of Assessments & $\begin{array}{c}\text { Current } \\
\text { Isotopic } \\
\text { Assessment }\end{array}$ & $\begin{array}{c}\text { Current } \\
\text { Overall } \\
\text { Assessment } \\
\end{array}$ \\
\hline Austin Wash & $?$ & $?$ & Yes & Yes & Cohesiveness of diagnostic stone tools: No & Yes & Yes \\
\hline Firehole Basin & & $?$ & No & No & & No & No \\
\hline Gailiun & & $?$ & $?$ & Yes & Lack of fawns: Yes & No & No \\
\hline Eden-Farson & & $?$ & No & No & $\begin{array}{l}\text { Nimmo's (1971) age demography: } \\
\text { No (but see Lyman's (1987) critique) }\end{array}$ & Yes & $?$ \\
\hline Boars Tusk & & ? & $?$ & $?$ & Fisher and Frison (2000) seasonality: Inconclusive & ve No & No \\
\hline Trappers Point & t Yes & $?$ & $?$ & & Vertical bone distribution: No & Yes & Yes \\
\hline
\end{tabular}

PS: Pronghorn seasonality, PD: Pronghorn demography. Yes: Supports multiple populations, No: Does not support multiple populations, ?: Inconclusive, Blank: Not Available. PS and PD are Lubinski's (1997, 2000a,b) assessments, except for Trappers Point which is based on Miller et al. (1999) supplemented with the work described in Fenner and Walker (2008). 


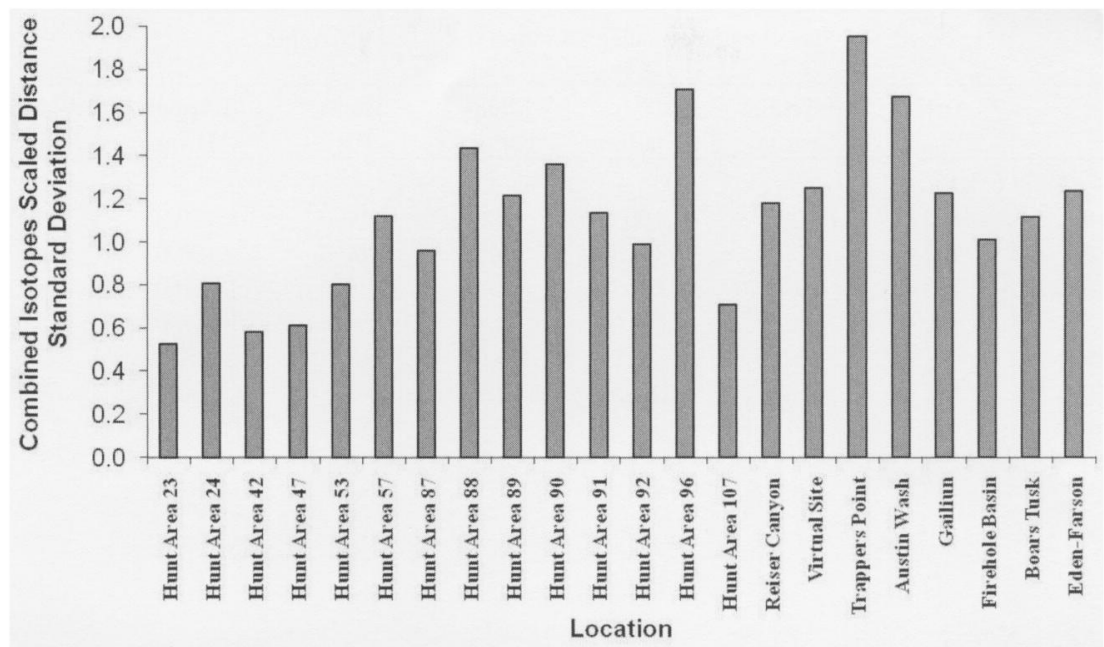

Figure 8. Comparison of carbon-oxygen scaled distance metric variation for modern hunt areas, the Reiser Canyon sample, a virtual site, and six archaeological sites. Minimum six samples per hunt area.

multiple population sources. Finally, it is less variable than nearly two-thirds of Reiser Canyon carbon-oxygen subsamples. The exception to the pattern is that Firehole Basin's carbon-oxygenstrontium distance variation is greater than the variation in 88 percent of Reiser Canyon's subsamples. Taken together, the isotope variation data clearly do not provide evidence of an accumulation of pronghorn from multiple populations at Firehole Basin.

Firehole Basin is located inside Hunt Area 59, and its mean strontium isotope value is indistinguishable from that of Hunt Area 59 (Table 4). The pronghorn thus are likely to have been local residents, and there is no reason not to accept a single mass kill scenario for Firehole Basin.

\section{Gailiun}

Isotope variation at the Gailiun site is generally not consistent with a multiple population accumulation. The comparative carbon-oxygen-strontium isotope variation (Figure 7) indicates that Gailiun has less variation than do most hunt areas, and only a bit more variation than Reiser Canyon. Gailiun's carbon-oxygen variation (Figure 8) is more impressive, being larger than the variation at 11 of 14 hunt areas (but again is only slightly larger than Reiser Canyon's variation). Quantitatively, Gailiun shows much less variation than the virtual site when using carbon-oxygen-strontium distance variation (Table 7). Using the less accurate (Fenner 2007:72-73,
2008) carbon-oxygen measure, Gailiun and the virtual site show essentially equal variation. Gailiun's carbon-oxygen-strontium variation is greater than the variation in less than half of subsamples from Hunt Areas 91 and 92. Gailiun's variation relative to Reiser Canyon of about 91 and 69 percent for the two isotope distances is, however, suggestive of multiple populations.

The Gailiun site isotopic variation data thus is somewhat equivocal but overall does not indicate an accumulation. Lubinski (1997, 2000a) considers Gailiun to be the result of an accumulation rather than a mass kill site (Table 6; see also the Previous Work section). My assessment, however, is that overall Gailiun does not show sufficient isotopic variation to support a designation as a multiple population accumulation site. Lubinski's analysis, which I argue uses methods that in general may not be reliable (see previous discussion), and which in this case is driven almost entirely by the absence of fawns in the sample, is not adequate to reverse the isotopic assessment.

It should be admitted that the difference between my assessment and that by Lubinski may simply be a result of the default conditions of the analytic techniques in use. The isotopic method seeks to demonstrate an accumulation from multiple populations, and if it cannot then it defaults to not indicating accumulation. Lubinski's method seeks to match archaeological population age characteristics to modern population characteristics, and if 
Table 7. Percentage of Hunt Area Subsamples in Which Each Archaeological Site has Greater Distance Variation than the Subsample.

\begin{tabular}{|c|c|c|c|c|c|c|c|}
\hline Location & $\begin{array}{l}\text { Austin } \\
\text { Wash }\end{array}$ & $\begin{array}{c}\text { Firehole } \\
\text { Basin }\end{array}$ & Gailiun & $\begin{array}{l}\text { Eden- } \\
\text { Farson }\end{array}$ & $\begin{array}{l}\text { Boars } \\
\text { Tusk }\end{array}$ & $\begin{array}{c}\text { Trappers } \\
\text { Point }\end{array}$ & $\begin{array}{c}\text { Virtual } \\
\text { Site }\end{array}$ \\
\hline \multicolumn{8}{|c|}{ Combined $\delta^{13} \mathrm{C}$ and $\delta^{18} \mathrm{O}$} \\
\hline Hunt Area 42 & 100.0 & 100.0 & 100.0 & 100.0 & 100.0 & 100.0 & 100.0 \\
\hline Hunt Area 47 & 100.0 & 100.0 & 100.0 & 100.0 & 100.0 & 100.0 & 100.0 \\
\hline Hunt Area 53 & 100.0 & 90.8 & 100.0 & 100.0 & 98.2 & 100.0 & 100.0 \\
\hline Hunt Area 57 & 99.9 & 40.5 & 71.6 & 73.1 & 54.5 & 100.0 & 75.6 \\
\hline Hunt Area 91 & 91.3 & 39.2 & 55.9 & 56.6 & 48.7 & 98.9 & 57.9 \\
\hline Hunt Area 92 & 100.0 & 58.3 & 86.5 & 87.5 & 72.0 & 100.0 & 88.7 \\
\hline Reiser Canyon & 98.2 & 34.7 & 69.2 & 70.2 & 52.1 & 99.8 & 71.4 \\
\hline \multirow{2}{*}{\multicolumn{8}{|c|}{$\begin{array}{l}\text { Combined } \delta^{13} \mathrm{C}, \delta^{18} \mathrm{O} \text {, and } \mathrm{Sr} \\
\text { Hunt Area } 42\end{array}$}} \\
\hline & & & & & & & \\
\hline \multicolumn{8}{|l|}{ Hunt Area 47} \\
\hline \multicolumn{8}{|l|}{ Hunt Area 53} \\
\hline \multicolumn{8}{|l|}{ Hunt Area 57} \\
\hline Hunt Area 91 & 93.9 & 43.6 & 45.0 & 63.9 & 46.1 & 84.7 & 86.5 \\
\hline Hunt Area 92 & 99.4 & 41.0 & 46.5 & 94.8 & 57.9 & 99.4 & 99.4 \\
\hline Reiser Canyon & 100.0 & 88.0 & 91.2 & 100.0 & 96.0 & 100.0 & 100.0 \\
\hline
\end{tabular}

The virtual site is included for comparison. Combined $\delta^{13} \mathrm{C}$ and $\delta^{18} \mathrm{O}$ : Subsample size 7 selected from locations with at least 12 samples. Combined $\delta^{13} \mathrm{C}, \delta^{18} \mathrm{O}$ and Sr: Subsample size 7 selected from locations with at least 9 samples. Virtual site subsample size: 7 .

low sample size causes a characteristic not to match then it defaults to indicating an accumulation. These differences in technique are most apparent when equivocal results are produced.

Gailiun's mean strontium ratio is quite unlike that of modern pronghorn from the hunt area in which it is located (Table 4). This suggests that the kill may have occurred while the pronghorn were away from their home area, which was presumably in the lower strontium ratio area to the west. Alternatively, the kill may have occurred in the pronghorn's home area, and the carcasses transported to the Gailiun site for processing. In the latter case, it might seem surprising to find teeth and other low utility remains at Gailiun, but ethnographic hunters sometimes transport entire fairly lightweight animals from the kill location to a camp or processing area (O'Connell and Marshall 1989; O'Connell et al. 1990). An eviscerated but otherwise intact pronghorn carcass weighs 33 to $42 \mathrm{~kg}$ (O'Gara 2004:243), which is within the ability of a human to carry for a fair distance. Northern Paiute informants described to Willard Park the method they used to carry a pronghorn or deer carcass (Fowler 1989:20). The animal was bled and its intestines removed. Skin was then stripped from the legs and used to tie the legs together and as a tumpline across the hunter's shoulders. In this manner the carcass was carried to camp, where it was skinned and butchered. Intact carcass transport seems especially likely if the hunters intended to process the hide or bones. Numerous ethnographic reports demonstrate the utility of pronghorn hide for clothing and bones for marrow and bone grease extraction (McCabe et al. 2004:77-84).

\section{Eden-Farson}

Eden-Farson's relative isotopic variability is difficult to interpret (Figures 7 and 8). Its carbonoxygen-strontium distance metric is greater than that of Reiser Canyon or any of the seven hunt areas. It is, however, less than that of the virtual site. Using carbon-oxygen distance, Eden-Farson is more variable than Reiser Canyon (though just barely) and 11 of 14 hunt areas.

The quantitative assessment shows that EdenFarson is only slightly less variable than the virtual site (Table 7). Eden-Farson is more variable than the median subsample variation from every hunt area, but in some cases (particularly Hunt Area 91), the difference is not large. Similarly, it is more variable than is Reiser Canyon, though not by a very large amount in carbon-oxygen distance.

These results suggest that Eden-Farson prong- 
Table 8. Modern and Projected Relative Humidity at Mass Kill Sites.

\begin{tabular}{lccccc}
\hline & & & \multicolumn{2}{c}{ Modern HA } & \multicolumn{2}{c}{ Projected } \\
Site & $N$ & Mean & Hunt & Growing Season & Site \\
Boars Tusk & 6 & -11.51 & 92 & 44.0 & RH $(\%)$ \\
Firehole Basin & 7 & -8.65 & 59 & 45.5 & 51 \\
Gailiun & 8 & -9.19 & 91 & 45.2 & 35 \\
\hline
\end{tabular}

horn are the result of an accumulation from multiple populations. The isotopic data is, however, equivocal. It does not seem strong enough to fully overturn the Nimmo (1971) and Lubinski (1997, $2000 \mathrm{~b}$ ) analyses, which were based on large sample sizes and agreed that Eden-Farson was the result of a single mortality event. My overall assessment, therefore, is that Eden-Farson's pronghorn formation history is currently indeterminate.

Eden-Farson's mean strontium isotope value is significantly different from that of its home Hunt Area 92 (Table 4). Its value is, however, intermediate between the means values of Hunt Area 92 and nearby Hunt Area 96. This may indicate that the pronghorn spent time in Hunt Area 96, or it may be an artifact of the size of the hunt areas. That is, the region within Hunt Area 92 along the border of Hunt Area 96 may in fact produce strontium isotope ratios intermediate between the two hunt area mean values.

\section{Boars Tusk}

Boars Tusk's relative isotopic variation also appears to be somewhat equivocal (Figures 7 and 8). It shows less carbon-oxygen-strontium variation than the virtual site and five of seven hunt areas, but more than Reiser Canyon. Its carbon-oxygen variation is less than that of the virtual site, Reiser Canyon, and six of 14 hunt areas. The quantitative assessment shows that Boars Tusk is clearly quite a bit less variable than is the virtual site (Table 7). Its carbonoxygen-strontium distance is more variable than 96 percent of Reiser Canyon subsamples, but its carbon-oxygen distance is close to the median of Reiser Canyon subsamples. Boars Tusk's carbonoxygen-strontium distance is also close to the median of Hunt Area 91 and 92 subsamples.

Except for the carbon-oxygen-strontium distance relative to Reiser Canyon, the isotopic variability indicators thus suggest that Boars Tusk pronghorn were collected from a single popula- tion. The Reiser Canyon exception is of some concern since Reiser Canyon carbon-oxygen-strontium distance is probably the best single isotopic indicator. Nevertheless, the overall isotopic assessment is that the pronghorn remains at the Boars Tusk site are less likely to have originated in multiple pronghorn populations than in a single population.

Boars Tusk pronghorn mean strontium values are substantially different from those of modern pronghorn in their home region of Hunt Area 92 (Table 4). The Boars Tusk values are more compatible with pronghorn from hunt areas to the northwest or southeast of Hunt Area 92. This indicates that the pronghorn spent substantial time outside of Hunt Area 92 during their tooth formation periods, which in turn suggests that they were killed during migration from one area to another. As at Gailiun, human transport of pronghorn carcasses is also a possibility.

\section{Trappers Point}

Trappers Point's relative carbon-oxygen-strontium isotopic distance variation (Figure 7) is only slightly less than that of the virtual site, and substantially exceeds the variation of Reiser Canyon and all modern hunt areas. Its carbon-oxygen variation is the largest measured, substantially exceeding that of the virtual site, Reiser Canyon and all modern hunt areas (Figure 8). The quantitative analysis supports this overall assessment (Table 7). The Trappers Point carbon-oxygen-strontium variability is about the same as that of the virtual site and greatly exceeds the variation in modern locations. Its carbon-oxygen variation substantially exceeds that in both the virtual site and all modern locations. The isotopic data strongly indicates that Trappers Point pronghorn were accumulated from multiple populations.

Trappers Point, however, presents a complication. As previously noted, it is located at a natural bottleneck between the Green River and the Wind 
River Mountains (Eckerle 1999; Sanders and Miller 2004). Modern pronghorn move through the area during spring migrations north into the Greater Yellowstone Area and return in the fall. Crucially, these migrations include pronghorn that originate in a wide swath of southwestern Wyoming (Sawyer and Lindzey 2000) and therefore would be expected to include substantial isotopic variability. If these migrations also occurred during the Early Archaic period, then isotopic analysis of Trappers Point pronghorn might not distinguish between multiple accumulations from multiple populations and a single accumulation from multiple populations that gathered together during a migration (although the radiocarbon dates would not be similarly affected). Multiple modern pronghorn groups congregate in the area just south of Trappers Point during spring migrations (Sawyer and Lindzey 2000:18), although this may be related to modern highway and housing developments in the area. The spring timeframe for at least some of the pronghorn at Trappers Point (Miller 1999; see also Fenner and Walker 2008) lends support to the possibility that its pronghorn were intercepted during migration (Miller et al. 1999b).

Strontium isotope ratios may provide insight into this problem. The mean Trappers Point archaeological strontium values are significantly different from those of Hunt Areas 87 and 88 (Table 4). It may be that some of the Trappers Point pronghorn spent much of their time during the period of enamel formation in a different location but were moving through the Trappers Point area as part of a routine, seasonal migration. If so, then hunters may have intercepted them during movement through a particularly small migration corridor. This could be further investigated through strontium isotope analysis of intra-tooth isotopic variation of archaeological samples. The possibility of multiple population accumulation through interception of migrating pronghorn is further explored in the following section.

The isotopic data in combination with the radiocarbon data discussed previously present a persuasive case that Trappers Point pronghorn remains are the result of at least two kill events substantially separate in time. It is difficult to reconcile this with the vertical distribution data, unless sediment accumulation in the area was very slow or intermittent. Overall, it seems quite likely that multiple occu- pations at Trappers Point harvested pronghorn from multiple populations. That these multiple populations formed during migration through the area remains a possibility.

\section{Conclusions}

Isotope ratio variation is a useful source of information when assessing whether an archaeological bonebed results from a single mass kill or an accumulation of animals from multiple populations. Archaeologists using isotope data in conjunction with other archaeological information will often improve their understanding of the formation processes of particular sites, and therefore of cultural and regional patterns.

With respect to pronghorn bonebeds in southwestern Wyoming, it appears that bonebeds at Austin Wash and Trappers Point are the result of accumulation from multiple populations and Firehole Basin is likely to be derived from a single population. Gailiun and Boars Tusk are less certain, but seem unlikely to be from multiple populations. The pronghorn population characteristics at the EdenFarson site are indeterminate.

It is interesting that Austin Wash and Trappers Point are the sites most likely to have been formed through accumulation, because they are also the two oldest sites in the sample (Table 1). Four explanations for this circumstance may be suggested. First, it may simply be a coincidence related to small sample size and therefore not indicative of any archaeological phenomenon. The only way to resolve this is to increase the sample size by finding and excavating more pronghorn bonebeds in the area. Second, diagenesis may have altered the archaeological site isotope ratios in the oldest sites. This does not, however, seem likely to be the case (see the Methods section for discussion).

The difference between Austin Wash and Trappers Point bonebed formation processes and those of later sites may reflect differences in the cultural groups that killed the pronghorn and deposited their remains. Specifically, Lubinski $(1997,2000$ a) tentatively proposed that mass pronghorn kills are indicative of the expansion of Numic cultural groups from the Great Basin into southwestern Wyoming between 500 and 700 B.P. The results of the current analysis are compatible with this hypothesis: the two sites identified as accumula- 
tions date to well before 700 B.P, and the sites identified as single pronghorn population sites consistent with mass kills occur during or after the period. While much more analysis of a variety of culturally diagnostic archaeological materials is needed to confirm the hypothesis, it is an intriguing possibility. It may be informative to perform similar analyses on Great Basin pronghorn bonebeds to determine whether the pattern holds in other time periods and regions.

Finally, perhaps Trappers Point and Austin Wash show evidence of accumulation because they involved interception of migrating pronghorn from multiple populations while the others resulted from a drive, surround, or trap of local pronghorn populations. Trappers Point, at least, clearly lies within a modern pronghorn migration corridor (Sawyer and Lindzey 2000). It is possible that the comparison of a site's mean strontium isotope values to mean values in pronghorn from the hunt area surrounding the site would distinguish between sites with local pronghorn and those with nonlocal, migrating pronghorn. The Trappers Point pronghorn mean strontium isotope ratio is significantly different from the mean of modern local pronghorn (Table 4). However, two other sites identified by isotope analysis as containing single-population bonebeds have strontium isotope means that are statistically different from their surrounding hunt areas, so nonlocal strontium signatures occur in both single- and multiple-population sites.

Having distinguished between multiple- and single-population archaeological bonebeds, it is now appropriate to consider what anthropological issues may best be investigated using each type of bonebed separately. Out of a range of possibilities, I will focus on two: the value of multipleaccumulation sites in foregrounding the reuse of a specific location on the landscape, and the reconstruction of specific environmental conditions using single-population bonebeds.

Both of the sites identified in this analysis as containing remains from multiple pronghorn populations are (like most archaeological sites) discard locations. While one may suppose that Trappers Point and Austin Wash were associated in some manner with nearby kill sites or camps, ultimately the only evidence recovered to date relates to the discard of a large number of pronghorn bones, a few bones from other animals, hundreds of lithics, and thousands of pieces of debitage in a very specific location. Both also had associated ash and fire-cracked rock suggestive of hearths or roasting pits. While not forgetting the possibility of temporary prey population aggregation during migration, the presence of multiple prey populations within each bonebed suggests that people visited the area more than once over a fairly short period during which the bonebed was exposed, and each time discarded their refuse in exactly the same location. The presence of a number of whole, intact lithics along with chipped stone debitage throughout each bonebed indicates that the bones were also processed in some manner (presumably involving defleshing) at the exact same locations.

Along these lines, it is interesting that Trappers Point and Austin Wash are both multicomponent sites. At Trappers Point, Stratum VII overlies and is stratigraphically separated from Stratum V (the focus of interest elsewhere in this report), which in turn overlies and is stratigraphically separated from Stratum III (Francis and Sanders 1999). While Stratum $V$ has by far the largest bonebed, all three strata include substantial bone deposits and are dominated by pronghorn remains. Austin Wash has been less thoroughly investigated than Trappers Point, and only the main component is well understood. However, radiocarbon dates obtained from nearby features suggest that there are at least two components spatially slightly outside the main bonebed (Schroedl 1985).

Thus, bone was processed and discarded at both Trappers Point and Austin Wash multiple times, and spanning two temporal scales. Deposition of bones from multiple independent prey populations suggest multiple events at an intermediate scale, during which the bonebed formed during a previous deposition event was still visible on the landscape, while the presence of multiple components separated by hundreds, perhaps thousands, of years indicate multiple events at the same exact location despite the probable invisibility of previous deposition events. What was it that drew people to preferentially process and discard pronghorn kills at those exact locations rather than elsewhere on the landscape? The association of location and discard behavior may be reflective of cultural history or may be associated with specific economic strategies (Holdaway and Wandsnider 2006). Trappers Point and Austin Wash do not seem to share spe- 
cific environmental features that would lead people to use those particular locations. Trappers Point is located near the crest of a low rise (one of many low rises in the area) while Austin Wash is on a gentle slope near the base of a steep cliff. Trappers Point is a few kilometers from the Green River (the only large river in the region) but is not directly associated with a modern water source, while the Austin Wash site is adjacent to the intermittent stream of the same name and an unnamed ephemeral drainage. The modern vegetation in both areas is dominated by sagebrush, but that is true of the most of the basin area of southwestern Wyoming. It thus is unlikely that physical features of the landscape caused people to repeatedly come to these particular locations for pronghorn processing. Instead, it seems likely that long-lasting cultural or historical features of the landscape made these attractive processing sites for people who successfully hunted pronghorn.

Turning now to the three sites identified in this analysis as resulting from mass kills of single pronghorn populations, we can consider the use of pronghorn bonebeds in reconstructing past environmental conditions. Gailiun, Firehole Basin, and Boars Tusk each contain the remains of a statistically meaningful sample of pronghorn from a single population and therefore a single snapshot of time. Analysis of modern pronghorn populations (Table 2) indicates that mean $\delta^{13} \mathrm{C}$ values are strongly correlated with growing season humidity $\left(r^{2}=.69, p<.001\right.$; Fenner and Frost 2009). A regression of this correlation can be used with mean $\delta^{13} \mathrm{C}$ values from archaeological single-population bonebeds to obtain a rough idea of humidity conditions at fairly specific times and places in the past (Table 8). The Boars Tusk humidity projection is substantially greater than its area's modern 30-year average growing season humidity, but is in line with humidity values from areas to the northeast such as Hunt Areas 64 and 75. More interesting are the humidity projections for Gailiun and Firehole Basin, which are well below the modern 30-year average growing season humidity values for any measured hunt area in Wyoming. It may be that very arid conditions increased the motivation or the opportunity for people to communally hunt pronghorn in southwestern Wyoming.

Full resolution of the implications of southwestern Wyoming pronghorn bonebed formation process differences must await a larger sample of bonebeds, which may involve expanding focus beyond southwestern Wyoming into surrounding regions. The current analysis has shown, however, that isotope analysis, in combination with other methods, can in some circumstances resolve the prey population formation history of large archaeological pronghorn bonebeds. It furthermore seems likely that the method can be adapted to use with bonebeds dominated by the remains of other species, such as bison.

Acknowledgments. I appreciate helpful discussions and comments on an earlier version of this article by Marcel Kornfeld, Todd Surovell, Carol Frost, David Williams, Mark Miller, and James Ahern. Anonymous reviewers also provided helpful comments on an earlier draft. The author would like to thank Martha Rogers, Joni Stainbrook, the University of Wyoming Archaeological Repository and Curation Facility and Western Archaeological Services for providing archaeological samples. Thank you also to Shay Westbrook and the Wyoming Game and Fish Department for providing the modern hunt area pronghorn teeth. Patrick Lubinski, Danny Walker, and the University of Wyoming Comparative Osteology Museum and Zooarchaeological Laboratory kindly provided the Reiser Canyon samples. Mike Meredith and Shikha Sharma provided help and good advice regarding isotope analysis. My thanks to Ranel Capron of the U.S. Bureau of Land Management for permission to sample enamel from pronghorn recovered from BLM sites. Kirk Nordyke of Wyoming Game and Fish Department provided a GIS shapefile of the pronghorn hunt areas. The Spanish translation of the abstract was provided by ASTAUSA. Funding for this project was provided by the University of Wyoming Department of Geology and Geophysics, National Science Foundation Doctoral Dissertation Improvement Grant \#44310, and a University of Wyoming Summer Doctoral Augmentation Award.

\section{References Cited}

Arkush, Brooke S.

1986 Aboriginal Exploitation of Pronghorn in the Great Basin. Journal of Ethnobiology 6:239-255.

Bartlein, Patrick J., Mary E. Edwards, Sarah L. Shafer, and Edward D. Barker, Jr.

1995 Calibration of Radiocarbon Ages and the Interpretation of Paleoenvironmental Records. Quartenary Research $44: 417-424$.

$\mathrm{BCal}$

2006 BCal: An on-line Bayesian radiocarbon calibration tool. Calibrated using the 2004 atmospheric calibration curve, http://bcal.shef.ac.uk.

Bentley, R. Alexander, T. Douglas Price, Jens Luning, Detlef Gronenborn, Joachim Wahl, and Paul D. Fullagar

2002 Prehistoric Migration in Europe: Strontium Isotope Analysis of Early Neolithic Skeletons. Current Anthropology 43:799-804.

Buntinas, Martin, and Gerald M. Funk 
2005 Statistics for the Sciences. Brooks/Cole, Belmont, California.

Byers, John A.

1997 American Pronghorn: Social Adaptations and the Ghosts of Predators Past. University of Chicago Press, Chicago.

2003 Built for Speed: A Year in the Life of Pronghorn. Harvard University Press, Cambridge.

Caughley, Graeme

1974 Interpretation of Age Ratios. Journal of Wildlife Management 38:557-562.

Chamberlin, Ralph V.

1911 The Ethno-Botany of the Gosiute Indians of Utah. Memoirs of the American Anthropological Association 2 Part 5:331-405.

Chittenden, Hiram Martin

1905 Life, Letters and Travels of Father Pierre-Jean De Smet, S. J.: 1801-1873, Volume 4. Francis P. Harper, New York.

Clark, Ian D., and Peter Fritz

1997 Environmental Isotopes in Hydrogeology. Lewis Publishers, Boca Raton.

Clayton, Carmen, and Raymond Kunselman

2002 Obsidian Source Utilization at the Trappers Point Antelope Kill Site 48SU1006. Wyoming Archaeologist 46(2):83-91.

Current, Bill

1993 Archaeological Data Recovery Plan for the Gailiun Site (48SU1156). Sublette County, Wyoming.

Davis, Leslie B., John W. Fisher, Jr., Michael C. Wilson, Stephen A. Chomko, and Richard E. Morlan

2000 Avonlea Phase Winter Fare at Lost Terrace, Upper Missouri River Valley of Montana: The Vertebrae Fauna. In Pronghorn Past and Present: Archaeology, Ethnography, and Biology. Plains Anthropologist Memoir 32., edited by Jana V. Pastor and Patrick M. Lubinski, pp. 53-69. Plains Anthropological Society, Lincoln, Nebraska.

De Smet, Pierre J.

1859 Western Missions and Missionaries: A Series of Letters. New York, P. J. Kennedy.

Dewar, Genevieve, Dave Halkett, Tim Hart, Jayson Orton, and Judith Sealy

2006 Implications of a Mass Kill Site of Springbok (Antidorcas Marsupialis) in South Africa: Hunting Practices, Gender Relations, and Sharing in the Later Stone Age. Journal of Archaeological Science 33:1266-1275.

Eckerle, William P.

1999 Paleoenvironmental Reconstruction and Prehistoric Lifeways. In The Trappers Point Site (48SU1006): Early Archaic Adaptations in the Upper Green River Basin, Wyoming, edited by Mark E. Miller, Paul H. Sanders, and Julie E. Francis, pp. 452-475. Cultural Resource Series No. 1. vol. 1. Office of the Wyoming State Archaeologist, Wyoming Department of State Parks and Cultural Resources, Laramie, Wyoming.

Eckles, David G.

1999 Taxonomic Identification, Bone Element Frequencies, and Bone Artifacts. In The Trappers Point Site (48SU1006): Early Archaic Adaptations in the Upper Green River Basin, Wyoming, edited by Mark E. Miller, Paul H. Sanders, and Julie E. Francis, pp. 193-205. Cultural Resource Series No. 1. vol. 1. Office of the Wyoming State Archaeologist, Wyoming Department of State Parks and Cultural Resources, Laramie, Wyoming.

Egan, Howard R.

1917 Pioneering the West 1846 to 1878. Howard R. Egan Estate, Richmond, Utah.
Ehleringer, James R., and Paul W. Rundel

1989 Stable Isotopes: History, Units, and Instrumentation. In Stable Isotopes in Ecological Research, edited by Paul W. Rundel, James R. Ehleringer and Kenneth A. Nagy, pp. 1-15. Springer-Verlag, New York.

Ericson, Jonathon E.

1985 Strontium Isotope Characterization in the Study of Prehistoric Human Ecology. Journal of Human Evolution 14:503-514.

Fawcett, William Bloys, Jr.

1987 Communal Hunts, Human Aggregations, Social Variation, and Climatic Change: Bison Utilization By Prehistoric Inhabitants of the Great Plains. Ph.D. Dissertation, Anthropology, University of Massachusetts, Amherst. ProQuest Dissertation Number AAT 8710451.

Fenner, Jack N.

2007 Prehistoric Hunting On the Range Where the Antelope Play: Archaeological Pronghorn Bonebed Formation Analysis. Ph.D. Dissertation, Department of Anthropology, University of Wyoming, Laramie. ProQuest Dissertation Number AAT 3259784.

2008 The Use Of Stable Isotope Ratio Analysis To Distinguish Multiple Prey Events From Mass Kill Events. Journal of Archaeological Science 35:704-716.

Fenner, Jack N. and Carol D. Frost

2009 Modern Wyoming Plant and Pronghorn Isoscapes and Their Implications for Archaeology. Journal of Geochemical Exploration, in press.

Fenner, Jack N., and Danny N. Walker

2008 Mortality Date Estimation Using Fetal Pronghorn Remains. International Journal of Osteoarchaeology $18: 45-60$.

Fisher, John W., Jr., and George C. Frison

2000 Site Structure and Zooarchaeology at the Boar's Tusk Site, Wyoming. In Pronghorn Past and Present: Archaeology, Ethnography, and Biology. Plains Anthropologist Memoir 32., edited by Jana V. Pastor and Patrick M. Lubinski, pp. 89-108. Plains Anthropological Society, Lincoln, Nebraska.

Fowler, Catherine S.

1989 Willard Z. Park's Ethnographic Notes on the Northern Paiute of Western Nevada, 1933-1944. University of Utah Anthropological Papers Number 114 1. University of Utah Press, Salt Lake City.

Francis, Julie E., and Paul H. Sanders

1999 Excavation Summary. In The Trappers Point Site (48SU1006): Early Archaic Adaptations in the Upper Green River Basin, Wyoming, edited by Mark E. Miller Paul H. Sanders and Julie E. Francis, pp. 38-57. Cultural Resource Series No. 1. vol. 1. Office of the Wyoming State Archaeologist, Wyoming Department of State Parks and Cultural Resources, Laramie, Wyoming.

Frison, George

2000 Observations on Pronghorn Behavior and Taphonomic Analysis of Bonebeds: Implications for Analysis of the Eden-Farson Pronghorn Kill. In Pronghorn Past and Present: Archaeology, Ethnography, and Biology. Plains Anthropologist Memoir 32, edited by Jana V. Pastor and Patrick M. Lubinski, pp. 29-37. Plains Anthropological Society, Lincoln, Nebraska.

Frison, George C.

1971 Shoshonean Antelope Procurement in the Upper Green River Basin, Wyoming. Plains Anthropologist $16: 258-284$.

1978 Animal Population Studies and Cultural Inference. Plains Anthropologist 23:44-52.

1991 Prehistoric Hunters of the High Plains. 2nd ed. Aca- 
demic Press, San Diego.

Frison, George C., and Charles A. Reher

1970 Age Determination of Buffalo by Teeth Eruption and Wear. Plains Anthropologist Memoir 7:46-50.

Garvie-Lok, Sandra, Tamara L. Varney, and M. Anne Katzenberg

2004 Preparation of Bone Carbonate for Stable Isotope Analysis: The Effects of Treatment Time and Acid Concentration. Journal of Archaeological Science 31:763-776.

Grinnell, George Bird

1923 [1972] The Cheyenne Indians: Their History and Ways of Life. University of Nebraska Press, Lincoln.

Hedges, R. E. M.

2002 Bone Diagenesis: An Overview of Processes. Archaeometry 44:319-328.

Higgins, Pennilyn, and Bruce J. MacFadden

2004 "Amount Effect" Recorded in Oxygen Isotopes of Late Glacial Horse (Equus) and Bison (Bison) Teeth from the Sonoran and Chihuahuan Deserts, Southwestern United States. Palaeogeography, Palaeoclimatology, Palaeoecology 206:337-353.

Hill, Matthew E., Jr.

2002 The Milnesand Site: Site Formation Study of a Paleoindian Bison Bonebed in Eastern New Mexico. Plains Anthropologist 47:323-337.

Hill, Matthew Glenn

2001 Paleoindian Diet and Subsistence Behavior on the Northwestern Great Plains of North America. Ph.D. Dissertation, Department of Anthropology, University of Wisconsin, Madison.. ProQuest Dissertation Number AAT 3012451.

Hillson, Simon

1986 Teeth. Cambridge University Press, Cambridge.

Hodell, David A., Rhonda L. Quinn, Mark Brenner, and George Kamenov

2004 Spatial Variation of Strontium Isotopes $(87 \mathrm{Sr} / 86 \mathrm{Sr})$ in the Maya Region: A Tool for Tracking Ancient Human Migration. Journal of Archaeological Science 31:585-601.

Holdaway, Simon J., and LuAnn Wandsnider

2006 Temporal Scales and Archaeological Landscapes from the Eastern Desert of Australia and Intermontane North America. In Confronting Scale in Archaeology: Issues of Theory and Practice, edited by Gary. Lock and Brian L. Molyneaux, pp. 183-202. Springer, New York.

Hoppe, Kathryn A.

2004 Late Pleistocene Mammoth Herd Structure, Migration Patterns, and Clovis Hunting Strategies Inferred from Isotopic Analyses of Multiple Death Assemblages. Paleobiology 30:129-145.

Hoppe, K. A., P. L. Koch, and T. T. Furutani

2003 Assessing the Preservation of Biogenic Strontium in Fossil Bones and Tooth Enamel. International Journal of Osteoarchaeology 13:20-28.

Hoskinson, Reed L., and John R. Tester

1980 Migration Behavior of Pronghorn in Southeastern Idaho. Journal of Wildlife Management 44:132-144.

Hyde, George S.

1968 Life of George Bent: Written From His Letters. University of Oklahoma Press, Norman.

Irving, Washington

1986 The Adventures of Captain Bonneville U.S.A. in the Rocky Mountains and the Far West. University of Oklahoma Press, Norman.

Karhu, Rory R., and Stanley H. Anderson

2006 The Effect of High-Tensile Electric Fence Designs on Big-Game and Livestock Movements. Wildlife Society Bulletin 34:293-299.
Kelly, Isabel T.

1932 [1986] Ethnography of the Surprise Valley Paiute. In A Great Basin Shoshonean Source Book, edited by David Hurst Thomas. Garland Publishing, New York.

Kindig, Jean Matthews

1987 An Evaluation of an Ethnohistoric Account of a Plains Indian Communal Hunt in the Boulder Valley, 1862. Southwestern Lore 53:17-27.

Klein, Richard G.

1982 Age (Mortality) Profiles as a Means of Distinguishing Hunted Species from Scavenged Ones in Stone Age Archeological Sites. Paleobiology 8:151-158.

Klein, Richard G., and Kathryn Cruz-Uribe

1984 The Analysis of Animal Bones from Archeological Sites. University of Chicago Press, Chicago.

Knight, Dennis H.

1994 Mountains and Plains: The Ecology of Wyoming Landscapes. Yale University, New Haven.

Knudson, K. J., T. D. Price, J. E. Buikstra, and D. E. Blom

2004 The Use of Strontium Isotope Analysis to Investigate Tiwanaku Migration and Mortuary Ritual in Bolivia and Peru. Archaeometry 46:5-18.

Koch, Paul L.

1998 Isotopic Reconstruction of Past Continental Environments. Annual Review of Earth and Planetary Sciences 26:573-613.

Koch, Paul L., Kathryn A. Hoppe, and S. David Webb

1998 The Isotopic Ecology of late Pleistocene mammals in North America: Part 1. Florida. Chemical Geology 152:119-138.

Koch, Paul L., Noreen Tuross, and Marilyn L. Fogel

1997 The Effects of Sample Treatment and Diagenesis on the Isotopic Integrity of Carbonate in Biogenic Hydroxylapatite. Journal of Archaeological Science 24:417-429.

Kohlmann, Stephan G.

2004 Population Dynamics and Modeling. In Pronghorn Ecology and Management, edited by Bart W. O'Gara and Jim D. Yoakum, pp. 644-674. University Press of Colorado, Boulder, Colorado.

Kohn, Matthew J., and Thure E. Cerling

2002 Stable Isotope Compositions of Biological Apatite. In Phosphates. Geochemical, Geobiological, and Materials Importance. Reviews in Mineralogy and Geochemistry, edited by Matthew J. Kohn, John Rakovan, and John M. Hughes, pp. 455-488. vol. 48. Mineralogical Society of America, Washington D. C.

Larson, Robert, Joe Bozovich, and Jack Krmpotich

1969 Preliminary Report on Farson Site \#48 SW 304. Wyoming Archaeologist 12(4):13-16.

Lee-Thorp, Julia, and Matt Sponheimer

2003 Three Case Studies Used to Reassess the Reliability of Fossil Bone and Enamel Isotope Signals for Paleodietary Analysis. Journal of Anthropological Archaeology 22:208-216.

2006 Contributions of Biochemistry to Understanding Hominin Dietary Ecology. Yearbook of Physical Anthropology 49:131-148.

Leopold, Luna B., and Claudio Vita-Finzi

2005 Archaeological Trash: Geomorphology and Early Human Occupation in Wyoming. Catena 62:1-13.

Levin, Naomi E., Thomas E. Cerling, Benjamin H. Passey, John M. Harris, and James R. Ehleringer

2006 A Stable Isotope Aridity Index for Terrestrial Environments. Proceedings of the National Academy of Science 103:11201-11205.

Lowie, Robert H.

1909 [1986] Anthropological Papers of the American 
Museum of Natural History: The Northern Shoshone. Volume 2 Part 2. In A Great Basin Shoshonean Source Book, edited by David Hurst Thomas. Garland Publishing, New York.

1924 [1986] Notes on Shoshonean Ethnography. Anthropological Papers of the American Museum of Natural History, Volume 20, Part 3. In A Great Basin Shoshonean Source Book, edited by David Hurst Thomas. Garland Publishing, New York.

Lubinski, Patrick M.

1997 Pronghorn Intensification in the Wyoming Basin: A Study of Mortality Patterns and Prehistoric Hunting Strategies. Ph.D. Dissertation, Department of Anthropology, University of Wisconsin, Madison.

1999 The Communal Pronghorn Hunt: A Review of the Ethnographic and Archaeological Evidence. Journal of California and Great Basin Anthropology 21:158-181.

2000a Prehistoric Pronghorn Hunting in Southwest Wyoming. In Pronghorn Past and Present: Archaeology, Ethnography, and Biology. Plains Anthropologist Memoir 32, edited by Jana V. Pastor and Patrick M. Lubinski, pp. 109-118. Plains Anthropological Society, Lincoln, Nebraska.

2000b A Comparison of Methods for Evaluating Ungulate Mortality Distributions. Archaeozoologica 11:121-134.

2001 Estimating Age and Season of Death of Pronghorn Antelope (Antilocapra americana Ord) by Means of Tooth Eruption and Wear. International Journal of Osteoarchaeology 11:218-230.

Lubinski, Patrick M., and Christopher J. O'Brien

2001 Observations of Seasonality and Mortality from a Recent Catastrophic Death Assemblage. Journal of Archaeological Science 28:833-842.

Lyman, R. Lee

1987 On the Analysis of Vertebrae Mortality Profiles: Sample Size, Mortality Type, and Hunting Pressure. American Antiquity 52:125-142.

Lytle, John C.

1969 Farson Site 48 SW 304. Wyoming Archaeologist 12(4):17-19.

McCabe, Richard E., Bart W. O'Gara, and Henry M. Reeves

2004 Prairie Ghost: Pronghorn and Human Interaction in Early America. University Press of Colorado, Boulder Colorado.

Middleton, Jessica L., Patrick M. Lubinski, and Michael D. Metcalf

2007 Ceramics from the Firehole Basin Site and Firehole Phase in the Wyoming Basin. Plains Anthropologist 52:29-41.

Miller, Mark E.

1999 Seasonality of the Early Archaic Trappers Point Pronghorn Bonebed. In The Trappers Point Site (48SU1006): Early Archaic Adaptations in the Upper Green River Basin, Wyoming, edited by Mark E. Miller, Paul H. Sanders and Julie E. Francis, pp. 206-241. Cultural Resource Series No. 1. vol. 1. Office of the Wyoming State Archaeologist, Wyoming Department of State Parks and Cultural Resources, Laramie, Wyoming.

Miller, Mark E. and Paul H. Sanders

2000 The Trappers Point Site (48SU1006): Early Archaic Adaptations and Pronghorn Procurement in the Upper Green River Basin, Wyoming. In Pronghorn Past and Present: Archaeology, Ethnography, and Biology. Plains Anthropologist Memoir 32., edited by Jana V. Pastor and Patrick M. Lubinski, pp. 39-52. Plains Anthropological Society, Lincoln, Nebraska.

Miller, Mark E., Paul H. Sanders, and Julie E. Francis 1999a The Trappers Point Site (48SU1006): Early Archaic Adaptations in the Upper Green River Basin, Wyoming. Cultural Resource Series No. 1. Office of the Wyoming State Archaeologist, Laramie, Wyoming.

1999b Intermountain Archaeology and the Trappers Point Site. In The Trappers Point Site (48SU1006): Early Archaic Adaptations in the Upper Green River Basin, Wyoming, edited by Mark E. Miller, Paul H. Sanders, and Julie E. Francis, pp. 476-489. Cultural Resource Series No. 1. vol. 2. Office of the Wyoming State Archaeologist, Wyoming Department of State Parks and Cultural Resources, Laramie, Wyoming.

Moore, David S., and George P. McCabe

1999 Introduction to the Practice of Statistics. W. H. Freeman, New York.

Nimmo, Barry W.

1971 Population Dynamics of a Wyoming Pronghorn Cohort from the Eden-Farson Site, 48SW304. Plains Anthropologist 16:285-288.

O'Connell, James F., K Hawkes, and N. Blurton Jones

1990 Reanalysis of Large Mammal Body Part Transport Among the Hadza. Journal of Archaeological Science 17:301-316.

O'Connell, James F., and Brendan Marshall

1989 Analysis of Kangaroo Body Part Transport among the Alyawara of Central Australia. Journal of Archaeological Science 16:393-405.

O'Gara, Bart W.

2004 Physiology and Genetics. In Pronghorn Ecology and Management, edited by Bart W. O'Gara and Jim D. Yoakum, pp. 231-273. University Press of Colorado, Boulder, Colorado.

O'Gara, Bart W., and Jim D. Yoakum

2004 Pronghorn Ecology and Management. University Press of Colorado, Boulder.

Ottman, Jim

1992 The Plunge: A Herd Falls to Its Death. Wyoming Wildlife 52:10-13.

Price, T. D., J. H. Burton, and R. A. Bentley

2002 The Characterization of Biologically Available Strontium Isotope Ratios for the Study of Prehistoric Migration. Archaeometry 44:117-135.

Price, T. Douglas, Clark M. Johnson, Joseph A. Ezzo, Jonathon Ericson, and James $\mathrm{H}$. Burton

1994 Residential Mobility in the Prehistoric Southwest United States: A Preliminary Study using Strontium Isotope Analysis. Journal of Archaeological Science 21:315-330

Reiss, David, and Danny N. Walker

1982 Pronghorn Utilization at 48UT390 in Southwestern Wyoming. Wyoming Contributions to Anthropology 3:1-25.

Reynolds, Timothy D.

1984 Daily Summer Movements, Activity Patterns, and Home Range of Pronghorn. Northwest Science 58:300-311

Sanders, Paul H.

1999 Investigation of Bone Weathering Stages, Age Composition, and Spatial Distributions of Lithic and Faunal Remains. In The Trappers Point Site (48SU1006): Early Archaic Adaptations in the Upper Green River Basin, Wyoming, edited by Mark E. Miller, Paul H. Sanders, and Julie E. Francis, pp. 364-451. Cultural Resource Series No. 1. vol. 2. Office of the Wyoming State Archaeologist, Wyoming Department of State Parks and Cultural Resources, Laramie, Wyoming.

Sanders, Paul H., and Mark E. Miller 
2004 Archaeological Evidence of Pronghorn (Antilocapra americana) Migration in the Upper Green River Basin of Wyoming: Implications for Wildlife Management. In Zooarchaeology and Conservation Biology, edited by R. Lee Lyman and Kenneth P. Cannon, pp. 164-177. University of Utah Press, Salt Lake City.

Sawyer, Hall, and Fred Lindzey

2000 Jackson Hole Pronghorn Study. Wyoming Cooperative Fish and Wildlife Research Unit, Laramie, Wyoming.

Schoolcraft, Henry R.

1860 History, Antiquities, Language, Ethnology, Pictography, Rites, Superstitions, and Mythology of the Indian Tribes of the United States, Volume IV. J. B. Lippincott, Philadelphia.

Schroedl, Alan R.

1985 Archaic and Late Prehistoric Adaptation in Southwestern Wyoming: The Frontier Pipeline Excavations. Bureau of Land Management Wyoming Cultural Resource Series Number 3.

SHPO

197948 SW1373 (Boars Tusk) Site Report. Copy on file at Wyoming State Historic Preservation Office Cultural Records Office, Laramie, Wyoming.

1981-1999 48UT390 (Austin Wash) Site Reports. CRM site reports provided by various organizations. Copy on file at Wyoming State Historic Preservation Office Cultural Records Office, Laramie, Wyoming.

Steele, Teresa E.

2003 Using Mortality Profiles to Infer Behavior in the Fossil Record. Journal of Mammalogy 84:418-430.

Steward, Julian $\mathrm{H}$.

1933 Ethnography of the Owens Valley Paiute. University of California Publications in American Anthropology and Ethnology 33(3):233-350.

1938 Basin-Plateau Aboriginal Sociopolitical Groups. Smithsonian Institution Bureau ofmerican Ethnology Bulletin 120. Smithsonian Institution, Washington DC.

Stiner, Mary C.

1990 The Use of Mortality Patterns in Archaeological Studies of Hominid Predatory Adaptations. Journal of Anthropological Archaeology 9:305-351.

1991a An Interspecific Perspective on the Emergence of the Modern Human Predatory Niche. In Human Predators and Prey Mortality, edited by Mary C. Stiner, pp. 149-185. Westview Press, Boulder.

1991b Introduction: Actualistic and Archaeological Studies of Prey Mortality. In HumanPredators and Prey Mortality, edited by Mary C. Stiner, pp. 1-13. Westview Press, Boulder.

Sundstrom, Linea

2000 Cheyenne Pronghorn Procurement and Ceremony. In Pronghorn Past and Present: Archaeology, Ethnography, and Biology. Plains Anthropologist Memoir 32., edited by Jana V. Pastor and Patrick M. Lubinski, pp. 119-132. Plains Anthropological Society, Lincoln, Nebraska.

Tieszen, Larry L., and Tim Fagre

1993 Carbon Isotope Variability in Modern and Archaeological Maize. Journal of Archaeological Science 20:25-40.

Todd, Lawrence C.

1987 Analysis of Kill-Butchery Bonebeds and Interpretation of Paleoindian Hunting. In The Evolution of Human Hunting, edited by M. Nitecki and D. Nitecki, pp. 225-266. Plenum Press, New York.

Todd, Lawrence C., Jack L. Hofman, and C. Bertrand Schultz 1992 Faunal Analysis and Paleoindian Studies: A Reexamination of the Lipscomb Bison Bonebed. Plains Anthropologist 37:137-165.

Todd, Lawrence C., David C. Jones, Robert S. Walker, Paul C. Burnett, and Jeffrey Eighmy

2001 Late Archaic Bison Hunters in Northern Colorado: 1997-1999 Excavations at the Kaplan-Hoover Bison Bonebed (5LR3953). Plains Anthropologist 46:125-147. Ugan, Andrew, Jason Bright, and Alan Rogers

2003 When Is Technology Worth the Trouble? Journal of Archaeological Science 30:1315-1329.

Whittaker, William E., and James G. Enloe

2000 Bison Dentition Studies Revisited: Resolving Ambiquity between Archaeological and Modern Control Samples. Archaeozoologica 11:113-120.

Widga, Chris

2004 Early Archaic Subsistence in the Central Plains: The Spring Creek (25FT31) Fauna. Plains Anthropologist 49:25-58.

Wilson, S. R., and G. K. Ward

1981 Evaluation and Clustering of Radiocarbon Age Determinations: Procedures and Paradigms. Archaeometry 23:19-39.

Yoakum, Jim D.

2004a Foraging Ecology, Diet Studies and Nutrient Values. In Pronghorn Ecology and Management, edited by Bart W. O'Gara and Jim D. Yoakum, pp. 447-502. University Press of Colorado, Boulder, Colorado.

2004b Habitat Conservation. In Pronghorn Ecology and Management, edited by Bart W. O'Gara and Jim D. Yoakum, pp. 571-630. University Press of Colorado, Boulder, Colorado.

Received July 6, 2007; Revised April 12, 2008; Accepted August 21, 2008. 